\title{
Heat Transfer Characteristics of Single Cone-Jet Electrosprays
}

\author{
M.J. Gibbons ${ }^{\mathrm{a}, *}$, A.J. Robinson ${ }^{\mathrm{a}}$ \\ ${ }^{a}$ Department of Mechanical, Manufacturing and Biomedical Engineering, Trinity College Dublin, the University of Dublin, Dublin 2, \\ Ireland.
}

\begin{abstract}
Spray cooling is an attractive proposition for thermal dissipation due to its high efficiency and markedly lower power requirements than more conventional air cooling systems. The local convective heat flux to single source cone-jet electrospray using thin foil thermography has been investigated parametrically. Two-phase electrospray cooling using ethanol is explored for multiple nozzle sizes $\left(D_{i}=0.33-1.37 \mathrm{~mm}\right)$, flow rates $\left(Q=2-16 \mu \mathrm{L} \mathrm{min}{ }^{-1}\right)$ and separation heights $(H=2.5-17.5 \mathrm{~mm})$. The results shows two distinct regimes of electrospray cooling; evaporative and pool electrospray cooling. Cooling performance was shown to be dependent on separation height and flow rate. Nozzle size was shown not to be a significant parameter except for small dependency for the smallest nozzle size tested. Importantly, the results demonstrate that very high peak heat transfer enhancement of up to 18.71 times over natural convection can be achieved with electrospray cooling for exceptionally low flow rates $\left(4 \mu \mathrm{L} \mathrm{min}{ }^{-1}\right)$.
\end{abstract}

Keywords: Electrospray, Local heat transfer, Two phase cooling, Spray cooling, Cone-jet cooling

\section{Introduction}

Effective thermal dissipation is crucial for maintaining acceptable electronic device performance and long term reliability. Traditional fan and natural convection based cooling has long been used as the standard for thermal management in consumer electronics due to their low cost, simplicity and robustness. Circuit miniaturisation has driven these conventional cooling technologies to a thermal management threshold. This is due to the increasing expectation on small form factor electronics to be more compact while also increasing performance. This trend has sparked the need for development of new and innovative thermal management technologies.

An emerging solution to this thermal management problem is electrospray cooling (EC). EC facilitates two phase cooling by utilizing Coulomb forces for energy efficient fluid atomization. A voltage is applied to a source nozzle, creating an electric field between it and the target ground electrode. When a sufficient electric field is applied to a suitable working fluid, the meniscus at the tip of the source nozzle will deform into the shape of a liquid cone (see Fig 1). At the apex of this cone a thin permanent jet is established which produces quasi monodisperse micron-sized charged droplets. Under certain operating conditions electrospraying can achieve droplet production from a few thousands to tens of millions of droplets per second $[1,2]$.

This "cone-jet" phenomena was first termed by Cloupeau and Prunet-Foch [1], who distinguished the cone-jet

\footnotetext{
* Corresponding author

Email address: Michael.Gibbons@tcd.ie (M.J. Gibbons)
}

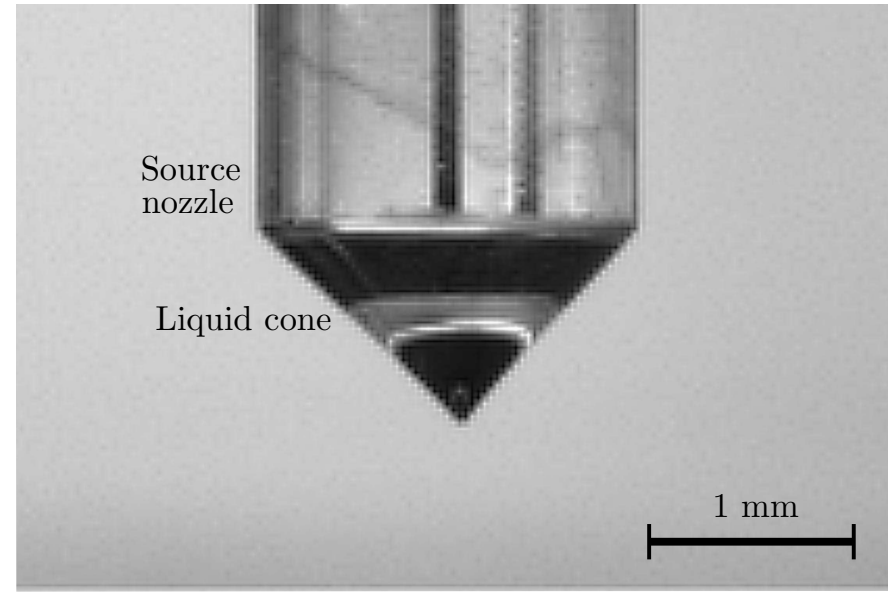

Figure 1: Electrospray cone-jet.

regime as well as a variety of other spraying modes [2]. The charged droplets that are generated are propelled by the potential difference that exists between the source nozzle and grounded target surface. Coulombic repulsion of the charged droplets enables self-spray dispersion (see Fig 2), while also preventing droplet coalescence. Additionally, these micron sized droplets can be generated from a source nozzle with a large bore relative to the droplet diameter. This reduces the flow resistance while also lowering the risk of blockage during spraying.

The voltage potential required to create an electrospray is dependent on the working fluid properties, spray system configuration and spraying regime being implemented, and can be achieved with very low hydraulic or additional elec- 


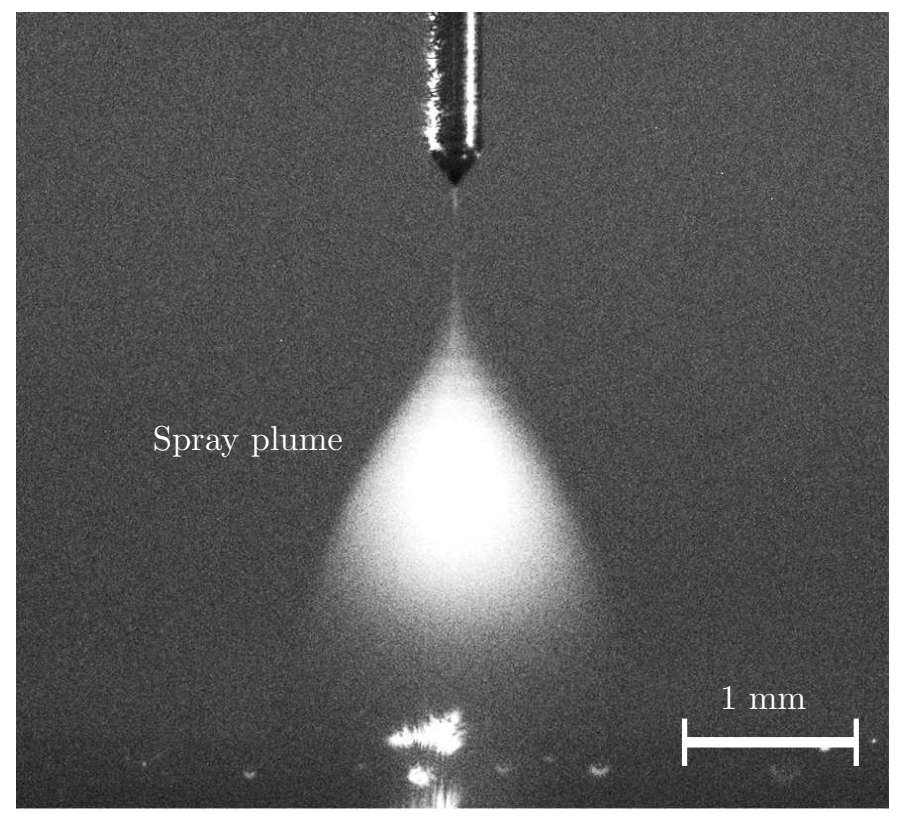

Figure 2: Electrospray plume.

trical energy requirements. By defining certain parameters such as working fluid properties, applied voltage and electrode configuration, one can precisely control droplet size, distribution and associated heat transfer $[2,3]$.

Electrospraying is an attractive proposition for cooling applications because it offers low profile liquid cooling performance for very small liquid flow rates due to its generation of monodisperse micron sized charged droplets [4-7], self spray dispersion due to Coulomb repulsions [4], negation of droplet rebound and increased droplet spreading upon impact due to Coulomb attraction [8]. This leads to a more effective heat transfer processes. Electrospraying can result in a hundredfold reduction in pressure drop in comparison with conventional fluid atomisers [3] and does not entail significant additional electrical power to operate. This makes EC technology particularly attractive for space applications, given the inherent size and weight restrictions coupled with the absence of buoyancy forces for natural convection cooling.

Prior research in the field of electrospray cooling is very limited. To this authors knowledge only three authors have published work pertaining to electrospray cooling. Their research, especially that of Deng and Gomez [3, 8], has shown that EC is a viable option as a thermal management solution for small form factor electronics.

Feng and Bryan [9] were the first to investigate two phase electrospray cooling (EC). Their research studied the average heat transfer enhancement of different nozzle arrays in an enclosed chamber under various spraying regimes with ethanol. They operating primarily outside the cone-jet mode. Their work showed that an optimum average heat transfer enhancement of 1.7 times over the no applied electric field case. This condition corresponded to a single nozzle, inner diameter $D_{i}=0.25 \mathrm{~mm}$, at their smallest nozzle - target separation height $H=5 \mathrm{~mm}$, for a flow rate of $Q=3000 \mu \mathrm{L} \mathrm{min}{ }^{-1}$. This fluid was deposited onto $50 \mathrm{~mm}^{2}$ surface with a heat flux of $10 \mathrm{~W} \mathrm{~cm}^{-2}$ and a fixed liquid layer appears to have been maintained on the heated substrate. The spraying regime was unspecified but an applied voltage of $7 \mathrm{kV}$ was noted. Due to the enclosed nature of their test section, a higher wall heat flux resulted in greater vapour momentum away from the surface minimizing the effect of some spraying regimes. The multiple source array enabled increased heat transfer enhancement at higher flow rates and lower heat fluxes.

Wang and Mamishev [10] investigated the average heat transfer of enclosed electrospraying chambers for three different geometry types in the multi-jet regime. They achieved a maximum average heat transfer enhancement of 1.87 fold over natural convection (NC) for their 8 source, $5 \mathrm{~mm}$ pitch array at the lowest wall heat flux of $4,384 \mathrm{~W} \mathrm{~m}^{-2}$. This case corresponded to a $H=7.5 \mathrm{~mm}, D_{i}=0.210 \mathrm{~mm}$ and $Q=133.33 \mu \mathrm{L} \mathrm{min}^{-1}$. Like Feng and Bryan, they noticed an increasing enhancement for decreasing wall heat fluxes. They stipulated that increasing the number of sources and their spacing does not improve the steady state heat transfer. However it does increase the transient average heat transfer performance. Wang and Mamishev [11] later developed a set of correlations for the average heat transfer enhancement ratio and Nusselt number for an electrospray operated in the multi-jet regime. Their model for the heat transfer enhancement over natural convection showed $83 \%$ agreement with their experimental data, within a $\pm 10 \%$ deviation. Their models performed well at lower flow rates with erroneous results appearing at higher flow rates. Wang and Mamishev stipulated that this was due to excessive coolant deposition on the target surface.

Deng and Gomez [3] constructed and tested 19 and 37 sourced multiplexed electrospray arrays with a source density of 253 sources $\mathrm{cm}^{-2}$. They operated in the cone-jet regime utilising an extractor design. An optimal average heat flux removal of $96 \mathrm{~W} \mathrm{~cm}^{-2}$ was noted for the highest

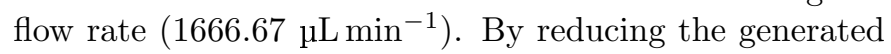
droplet size through increasing the electrical conductivity of the working fluid, they achieved an increase in average heat flux removal of $25 \%$ compared to the undoped ethanol case. From these results Deng and Gomez [3] suggested that producing the smallest droplets at the highest rate would optimise both spray efficiency and average heat flux removed. This can be achieved by optimising the packing of source nozzles to achieve small droplets for larger total flow rates.

Unlike past research, all of which focused on surface averaged convective heat transfer, this research endeavors to be the first to investigate the local convective heat flux distributions resulting from a single nozzle electrospray in the cone-jet mode regime under two-phase cooling conditions. This was achieved using an electrically heated thin foil and thermal imaging system in order to fully investigate and characterise the local heat transfer features of the electrospray under varied operating conditions. Specif- 


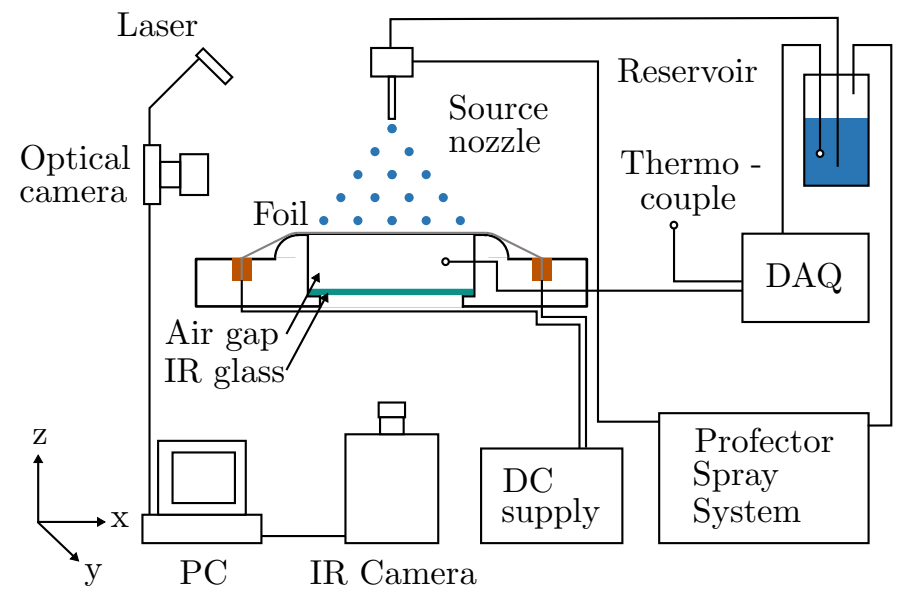

Figure 3: Schematic diagram of experimental set-up.

ically, ultra-low flow rates of ethanol are studied in this investigation.

\section{Experimental Apparatus and Data Reduction}

The experimental apparatus consists of three primary components; the heat transfer section, the electrospray generation and imaging system. These are illustrated in the rig schematic in Fig 3.

\subsection{Heat transfer section}

The thermal exchange section (shown in Fig 4) consists of a $25 \mu \mathrm{m}$ thick, $140 \times 80 \mathrm{~mm}^{2}$ Goodfellow Stainless Steel 316 (Fe/Cr18/Ni10/Mo3) foil (Fig 4d). The foil is clamped between two copper bus bars (Fig 4c), with both bus bars electrically connected to a Lambda GENESYS 6-200 DC power supply (Fig 6c). The copper bus bars are mounted to a polyrtheretheketone (PEEK) housing. This PEEK housing is shown in Fig 4a. A tensioning system is employed in order to counteract foil warping at higher foil temperature gradients. One set of bus bars are rigidly fixed to the PEEK housing while the other is spring loaded. The $25 \mu \mathrm{m}$ foil is stretched across a $140 \times 100 \times 13 \mathrm{~mm}^{3}$ central PEEK piece shown in Fig $4 \mathrm{~b}$.

The central PEEK piece serves to house a $70 \times 70 \times 2$ $\mathrm{mm}^{3}$ infrared (IR) transparent Calcium Fluoride $\left(\mathrm{CaF}_{2}\right)$ window. The top of this IR window is positioned $7 \mathrm{~mm}$ below the underside of the foil. This configuration establishes a $71 \times 71 \times 7 \mathrm{~mm}^{3}$ air cavity. During experimentation this trapped air acts as a thermal barrier, ensuring that the heat lost through conduction on the underside of the foil is low. A $1.6 \mathrm{~mm}$ exposed T-type thermocouple is used to measure the air temperature at the midpoint of the air gap cavity. The underside of the foil is exposed for direct temperature measurement by an infrared camera. It is coated with a thin layer of matt black paint of known emissivity to facilitate accurate temperature measurement.

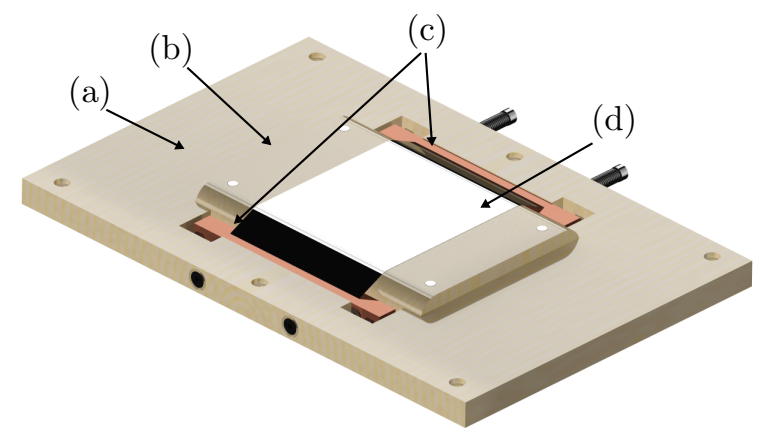

Figure 4: Thermal exchange section. (a) PEEK housing, (b) Central PEEK piece, (c) Copper bus bars, and (c) Stainless steel foil.

Table 1: Foil and paint properties.

\begin{tabular}{lrl}
\hline Foil thickness, $\delta_{f}$ & 25 & $\mu \mathrm{m}$ \\
Density, $\rho_{f}$ & 7960 & $\mathrm{~kg} \mathrm{~m}^{-3}$ \\
Thermal conductivity, $k_{f}$ & 16.3 & $\mathrm{~W} \mathrm{~m}^{-1} \mathrm{~K}^{-1}$ \\
Specific heat, $\mathrm{C}_{p, f}$ & 502 & $\mathrm{~J} \mathrm{~kg}^{-1} \mathrm{~K}^{-1}$ \\
${\text { Surface Roughness, } R a_{f}}$ & 59.52 & $\mathrm{~nm}$ \\
$\mathrm{CaF}_{2}$ Emissivity, $\varepsilon_{C a F_{2}}$ & 0.2 & - \\
${\text { Paint layer thickness, } \delta_{p}}$ & 10.52 & $\mu \mathrm{m}$ \\
Density, $\rho_{p}$ & 1261 & $\mathrm{~kg} \mathrm{~m}^{-3}$ \\
Thermal conductivity, $k_{p}$ & 0.095 & $\mathrm{~W} \mathrm{~m}^{-1} \mathrm{~K}^{-1}$ \\
Specific heat, C \\
Paint Emissivity, $\varepsilon_{p}$ & 2835 & $\mathrm{~J} \mathrm{~kg}^{-1} \mathrm{~K}^{-1}$ \\
& 0.95 & - \\
\hline
\end{tabular}

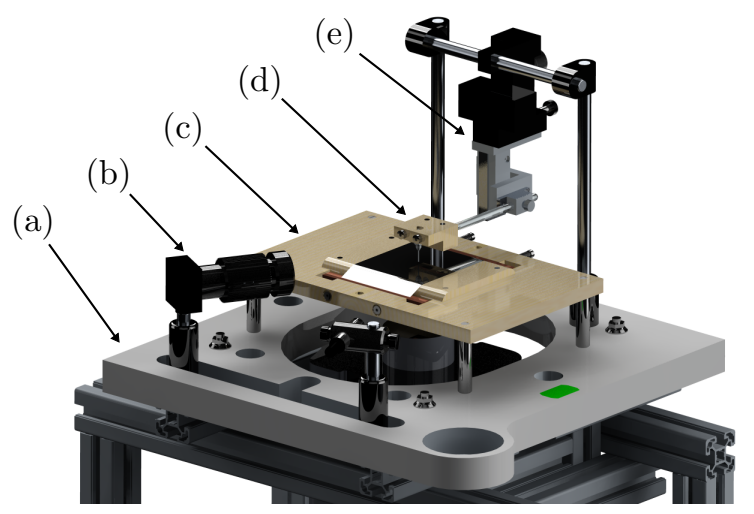

Figure 5: Electrospray baseplate configuration. (a) Ertacetal baseplate, (b) Optical camera. (c) Thermal exchange section, (d) Source nozzle, and (e) XYZ micropositioner.

\subsubsection{Material Properties}

The foil and paint properties are outlined in Table 1. The paint thickness was determined using a Dektak $6 \mathrm{~m}$ programmable surface profiler. The foil properties were defined using the supplier data sheet, while the paint layer was determined from data tabulated by Donoghue [12] and Raghu and Philip [13]. The surface roughness of the steel foil was determined using a MicroXAM White light Interferometric Surface Profiler. 


\subsection{Electrospray Generation System}

The thermal exchange section is mounted on a Ertacetal baseplate (Fig 5a), $400 \times 320 \times 30 \mathrm{~mm}^{3}$, and is supported on a $40 \times 40 \mathrm{~mm}^{2}$ aluminium profile frame. The applied nozzle voltage and flow rate pressure head are supplied and controlled by a Spraybase controller (Fig 6b). The Spraybase controller can supply $0-30 \mathrm{kV}$ DC voltage at $0.01 \mathrm{kV}$ increments and $0-5$ bar pressure head at 1 mbar increments. The spray source (Fig 5d) was a Luer lock stainless steel nozzle. A XYZ micro positioner (Fig 5e) is implemented to control placement of the source nozzle. The separation height can be accurately set to \pm $0.5 \mu \mathrm{m}$. The working fluid flow rate was monitored using a Sensirion SLI-0430 flow meter which reads to a resolution of $0.02 \mu \mathrm{L} \mathrm{min}{ }^{-1}$.

\subsection{Imaging system}

The imaging system consisted of two parts; a Chameleon CMLN-1352M optical camera and a FLIR SC6000 thermal imaging camera. Both cameras are controlled by a dedicated computer. The optical camera is mounted to the Ertacetal baseplace as shown in Fig 5a. It was used to focus on the source nozzle and define cone-jet spraying during testing.

A FLIR SC6000 high resolution, high frame rate IR camera was used to capture the thermal footprint of the electrospray plume. The camera is mounted to the aluminium profile, directly below the thermal exchange surface as shown in Fig 6a. The IR camera is fitted with a $25 \mathrm{~mm}$ focal length lens. The frame rate and capturing period is controlled via an external pulse generated by a National Instruments (NI) 9263 Data Acquisition Module (DAQ) in LabVIEW. The thermal camera is set to record an image that is $400 \times 400$ pixels with each pixel corresponding to a width of $157 \mu \mathrm{m}$. After a test is completed the acquired raw data is exported in a .sfmov file extension and is later processed using MATLAB.

\begin{tabular}{lrc} 
Table 2: Recording frequency of data acquisition & & \\
\hline IR camera & 200 & $\mathrm{~Hz}$ \\
Optical camera & 15 & $\mathrm{~Hz}$ \\
Foil voltage drop, $V_{s}$ & 50 & $\mathrm{~Hz}$ \\
Foil Current, $I_{s}$ & 50 & $\mathrm{~Hz}$ \\
Flow rate, $Q$ & 2 & $\mathrm{~Hz}$ \\
Air gap temperature $T_{a g}$ & 1.8 & $\mathrm{~Hz}$ \\
Ambient temperature $T_{\infty}$ & 1.8 & $\mathrm{~Hz}$ \\
Working fluid temperature $T_{w f}$ & 1.8 & $\mathrm{~Hz}$ \\
\hline
\end{tabular}

\subsection{Experimental parameters}

All tests were conducted in the cone-jet regime of spraying. The applied voltage and flow rate ranged between $2-$ $5 \mathrm{kV}$ and $2-16 \mu \mathrm{L} \mathrm{min}{ }^{-1}$ respectively during experimentation. The nozzle to target height was varied from $2.5-$ $17.5 \mathrm{~mm}$ in increments of $2.5 \mathrm{~mm}$. Four inner diameter nozzle sizes were characterised; $D_{i}=0.330,0.712,1.066$, and $1.371 \mathrm{~mm}$.
The working fluid used was pure 190 proof ethyl alcohol, with a boiling point of $78.37^{\circ} \mathrm{C}$. Experiments were conducted at atmospheric pressure and room temperature after steady state conditions were reached. The heated substrate temperature was assumed to be uniform across its thickness at a constant heat flux generation of 1,395 $\mathrm{W} \mathrm{m}{ }^{-2}$ for all test points. This corresponded to a surface temperature $\left(T_{s}\right)$ of $\sim 90^{\circ} \mathrm{C}$ in the absence of EC. This was confirmed by modelling the foil and paint layer in COMSOL $4.3 \mathrm{a}$ and through calculation of their respective Biot numbers, which were both $\ll 1$.

\subsection{Experimental procedure}

Prior to each test, the separation height, nozzle size, flow rate and surface heat flux are set. The working fluid coolant is primed to the nozzle tip and a dripping regime is established. The applied voltage is then adjusted to the onset voltage of the cone-jet regime. Once cone-jet spraying is established, the spray is allowed 15 minutes to reach steady state. Data acquisition is triggered using an in-house code developed in LabVIEW. Once the program is started it triggers the thermal imaging camera and optical camera, while simultaneously acquiring thermocouple, flow rate, foil voltage drop and circuit current readings. Data is acquired over a 10 second period. The recording rates of all relevant parameters are outlined in Table 2.

\subsection{Data analysis and processing}

The captured thermal images are processed using MATLAB. Processing of data can be divided into three phases; image conversion, heat transfer analysis and averaging.

\subsubsection{Image conversion}

For each test point the captured .sfmov video file is imported into MATLAB. Each frame is extracted and the

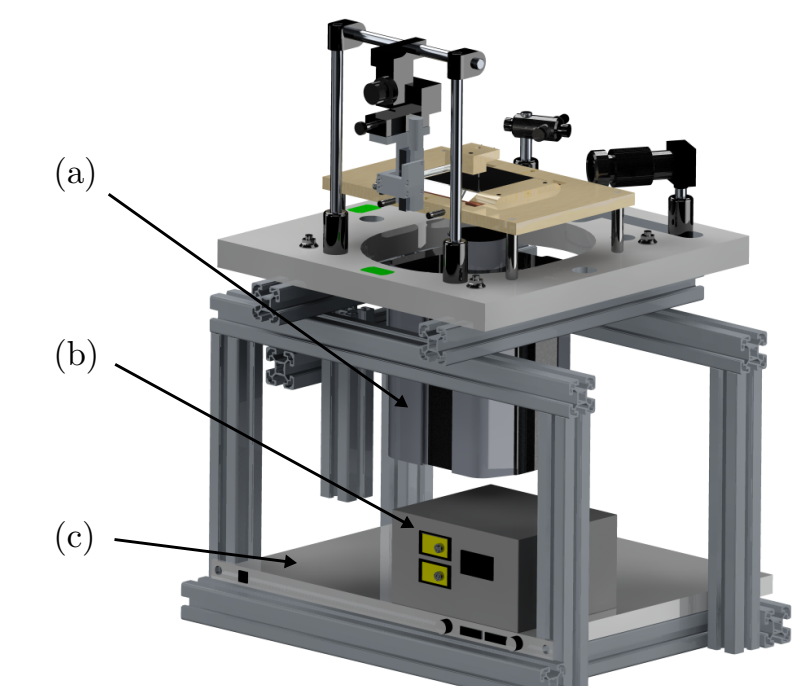

Figure 6: Electrospray rig. (a) IR camera, (b) Profector spray system, and (c) DC power supply. 
bad pixel, gain, offset and counts to temperature conversion are applied. This results in $2000400 \times 400$ thermal images stored in a 3D array.

\subsubsection{Heat transfer analysis}

In order to compute the thermal energy convected to the electrospray, various fluid, foil and paint properties (see Table 1) are input along with the averaged values for the relevant acquired data (thermocouple, flow rate, foil voltage drop and circuit current). In order to evaluate the thermal energy convected to EC, an element by element based energy balance is applied to each pixel of the recorded thermal image. The energy balance can be defined as [14]:

$$
\dot{E}_{i n}+\dot{E}_{g e n}-\dot{E}_{\text {out }}=\dot{E}_{c a p}
$$

It is assumed that there is uniform heat generation within the foil and that the temperature across the thickness of the foil and paint layers are constant as $\mathrm{Bi} \ll 1$ for both the paint and foil layers. This results in the following expression for the convective heat flux due to $\mathrm{EC}\left(q_{E C}^{\prime \prime}\right)$ :

$$
q_{E C}^{\prime \prime}=q_{g e n}^{\prime \prime}-q_{c o n d}^{\prime \prime}-q_{r a d, b}^{\prime \prime}-q_{l c}^{\prime \prime}-q_{c a p}^{\prime \prime}
$$

where $q_{\text {gen }}^{\prime \prime}$ is the heat flux generated in the foil by Joule heating given by Equation 3. The second term on the RHS accounts for heat lost through conduction across the air gap cavity and is given by Equation 4 , where $k_{a g}$ is the thermal conductivity of the bulk fluid (air) and $d T / d z$ is the temperate gradient across the air gap to the IR window. $q_{r a d, b}^{\prime \prime}$ is the total radiative emission from the underside of the foil to the top of the IR transparent $\mathrm{CaF}_{2}$ window and is given by Equation 5. The fourth term in Equation 2 refers to heat transfer due to lateral conduction shown in Equation 6. The partial derivative is solved by means of a central-difference approach using the inbuilt de12 MATLAB function. The final term accounts for the energy stored within the foil between images, also known as the capacitance term, Equation 7. This is found using the gradient function in MATLAB.

$$
\begin{gathered}
q_{g e n}^{\prime \prime}=\frac{I_{s} V_{s}}{A_{s}} \\
q_{\text {cond }}^{\prime \prime}=-k_{a g} \frac{d T}{d z} \\
q_{r a d, b}^{\prime \prime}=\frac{\sigma\left(T_{s}^{4}-T_{C a F_{2}}^{4}\right)}{1 / \varepsilon_{p}+1 / \varepsilon_{C a F_{2}}-1} \\
q_{l c}^{\prime \prime}=-\left(k_{f} \delta_{f}+k_{p} \delta_{p}\right)\left(\frac{\partial^{2} T_{s}}{\partial x^{2}}+\frac{\partial^{2} T_{s}}{\partial y^{2}}\right) \\
q_{c a p}^{\prime \prime}=\left(\rho_{f} C_{p, f} \delta_{f}+\rho_{p} C_{p, p} \delta_{p}\right) \frac{\partial T_{s}}{\partial t}
\end{gathered}
$$

\subsubsection{Averaging}

The final stage of processing is to average all images over each test. This assumes that the electrospray cooling is quasi-steady during the 10 second capture period. As will be discussed, this assumption is shown to be valid due to the relatively low calculated energy storage term. The

\begin{tabular}{|c|c|c|c|c|c|}
\hline Parameter & & $\mathrm{EU}$ & Unit & & PU [\%] \\
\hline$T_{s}$ & \pm & 0.77 & $\mathrm{~K}$ & \pm & 0.25 \\
\hline$T_{\infty}$ & \pm & 0.05 & K & \pm & 0.016 \\
\hline$T_{a g}$ & \pm & 0.06 & K & \pm & 0.016 \\
\hline$Q$ & \pm & $\begin{array}{r}0.04- \\
3.52\end{array}$ & $\mu \mathrm{L} \min ^{-1}$ & \pm & $\begin{array}{c}20.4 \\
21.7\end{array}$ \\
\hline$q_{g e n}^{\prime \prime}$ & \pm & 5.56 & $\mathrm{~W} \mathrm{~m}^{-2}$ & \pm & 0.38 \\
\hline
\end{tabular}
radial profile of the convective heat flux is then found by taking a line radially from the centre of the convective heat flux map in $1^{\circ}$ increments and averaging the results. An example of this resultant profile can be seen in Fig 8 and 9.

Table 3: Experimental uncertainty.

\section{Uncertainty Analysis}

The experimental uncertainty for all parameters was implemented using the methodology outlined by Kirkup and Frenkel [15]. A list of the relevant parameter and their associated expanded uncertainty (EU) and percentage uncertainty (PU) are outlined in Table 3. All listed values are to a $95 \%$ confidence level. First the standard uncertainty (SU) of the acquired test data was determined. A combined uncertainty approach was then applied on a pixel by pixel basis to Equation 2 - 7. The uncertainty of the foil surface temperature is the experimental standard deviation of the mean. This approach was taken due to the high autocorrelation value attached to sequential $T_{s}$ values. This uncertainty was determined from the calibration curve fit, accounting for the uncertainty attached to the polynomial fit between counts (IR camera data acquisition) and temperature. The expanded uncertainty for the radial profile of $q_{E C}^{\prime \prime}, q_{l c}^{\prime \prime}, q_{c a p}^{\prime \prime}, q_{\text {rad,b }}^{\prime \prime}$, and $q_{c o n d}^{\prime \prime}$ are shown graphically in Figure 8 and 9 . These values are highlighted at three key points on the radial profile. The $q_{l c}^{\prime \prime}$ term possess the largest attached uncertainty with an expanded uncertainty of $\pm 173.8 \mathrm{~W} \mathrm{~m}^{-2}$ and dominates the uncertainty analysis. This results in a typical expanded uncertainty of $\pm 174.5 \mathrm{~W} \mathrm{~m}^{-2}$ for the $q_{E C}^{\prime \prime}$ term.

\section{Results and Discussion}

\subsection{Electrospray process on a heated substrate}

The electrospray process is illustrated in Fig 7. Electrospray cooling can be divided into five distinct phases; cone formation (1), jet formation (2), droplet creation (3), droplet transit (4), and droplet impact and heat transfer (5). 


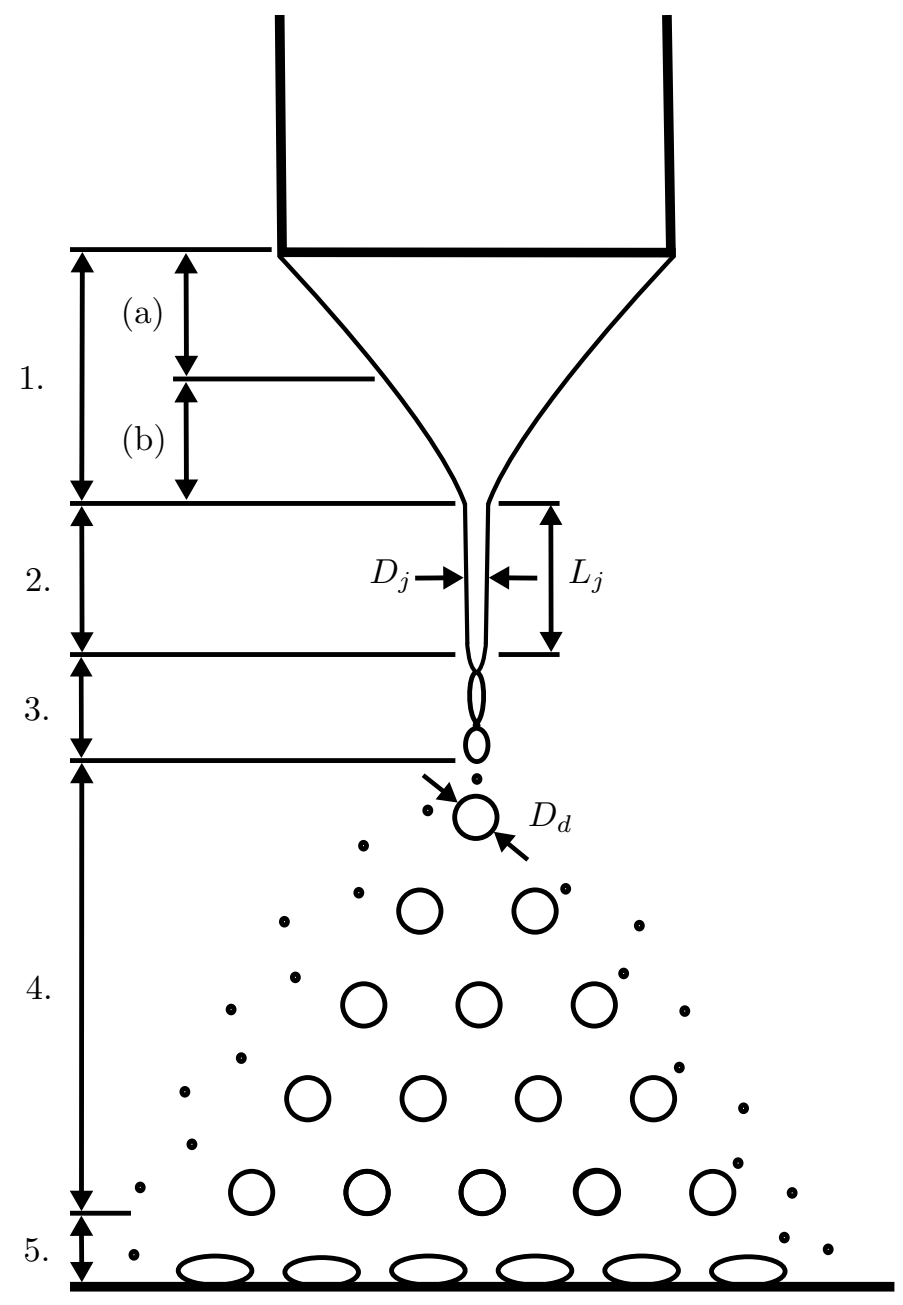

Figure 7: Electrospraying process.

In cone formation the applied electric field distorts the meniscus into the shape of a cone. The shape of this cone is defined by a balance of surface tension, hydrostatic, gravitational, inertial, viscous and electrical forces [16]. The cone itself can be split into two distinct sections, defined by the primary means of charge transportation. The first (1(a)) by conduction and the second (1(b)) through convection. This second zone is often termed the acceleration zone. The size of this acceleration region is dependent on the electrical conductivity of the working fluid. If the electrical conductivity is high the acceleration zone is localised to the tip of the cone with the rest of the cone $(1(\mathrm{a}))$ in a state of static equilibrium. Conversely, if the electrical conductivity is low the acceleration zone grows and extends towards the base of the cone. If the acceleration zone extends beyond the base of the cone then the cone may behave asymmetrically [16, 17].

At the apex of the cone a permanent jet forms. The length $\left(L_{j}\right)$ and width $\left(D_{j}\right)$ of this jet is dependent on the surface tension, viscosity, electrical conductivity and flow rate of the working fluid $[1,18]$.

Droplets produced in the cone-jet regime can be mono or poly disperse in nature depending on their break-up condition. Satellite droplets can accompany the primary droplet production [17, 18]. These break-up conditions can be split into two regimes; varicose and kink instabilities, with the former producing monodisperse and the later polydisperse droplets. They are defined dependent on the spray current. For the monodisperse case, if the spray current is sufficient this jet will break up in a similar manner to that of an uncharged jet [17]. It has been shown that the droplet diameter $\left(D_{d}\right)$ produced by varicose instabilities depends directly on the jet thickness $\left(D_{j}\right)$. The following relationship was defined for low viscosity fluids [17, 18]:

$$
D_{d}=1.89 D_{j}
$$

Following the empirical scaling law demonstrated by Deng and Gomez [3] for electrospraying with pure ethanol, a droplet size range of $D_{d} \sim 3.7-10.9 \mu \mathrm{m}$ is calculated for the investigated flow rate range of this study. Generated charged droplets are propelled to the grounded target surface by the applied electric field and surrounding gravitational force [19]. While in transit, the similarly charged nature of the droplets enables plume dispersion and inhibits droplet coalescence [20]. Segregation of primary and satellite droplets in the spray plume has been noted [4, 21] and corroborated by numerous authors, with the spray core consisting principally of primary droplets with satellite droplet orientated on the periphery of the plume. These satellite droplets are segregated by inertial and electrostatic effects [22] and make up $\approx 3 \%$ of the total flow rate and $\approx 15 \%$ of the total charge [4]. These smaller droplets move at a lower velocity relative to the central spray core due to the radial decay of the electric field [23].

Electrospray droplet impact and evaporation can be split into three phases; impact, recoil and and quasi-steady evaporation [8]. Deng and Gomez suggested a relatively gentle impact with dimensionless values corresponding to Weber number $(W e) \sim O(10)$ and Ohnesorge $(O h) \sim$ $O(0.1)$ for an electrospray generated charge droplet impacting on a grounded surface. During the impact phase the droplet contacts the substrate and deforms from a sphere to a liquid disk reaching a maximum spread diameter. In the recoil phase the surface tension drives the liquid back to a liquid hemispherical cap, which may oscillate several times after the initial recoil. The impacted stationary droplet then enters quasi-steady evaporation period, which continues until the droplet is completely evaporated [8]. Deng and Gomez showed that the droplet charge enables an image force between it and the grounded target substrate resulting in an avoidance of bouncing and reduction of contact angle resulting in greater droplet spreading and a more effective heat transfer process.

The highest local heat transfer for an evaporating droplet occurs at the contact line [24]. The contact line or triple line is defined as the region where the gas, liquid and solid phases intersect. It can be broken-up into four distinct regions: micro-convection region, intrinsic meniscus region, 


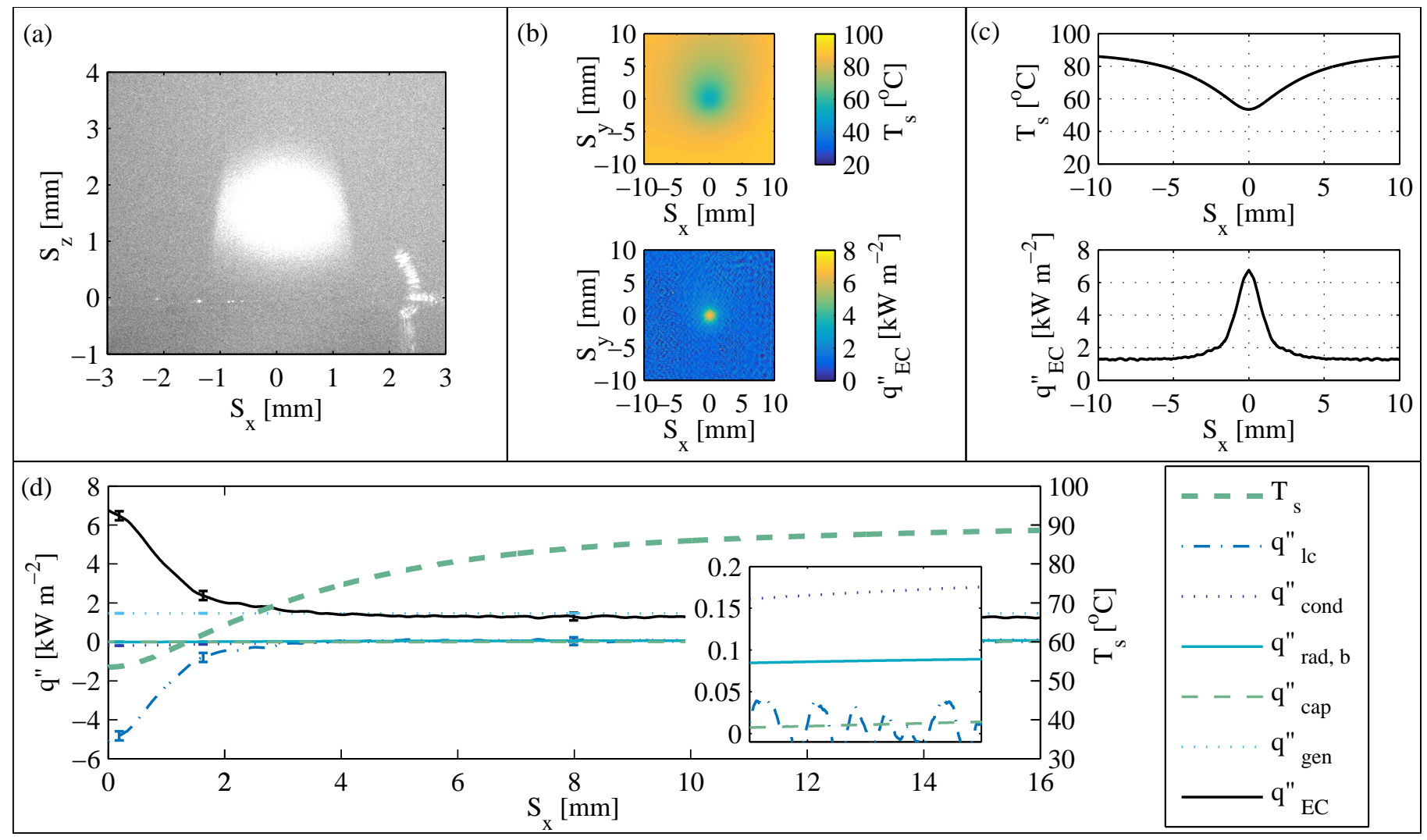

Figure 8: Radial evaporative energy balance. $V_{n}=3 \mathrm{kV}, D_{i}=0.330 \mathrm{~mm}, D_{o}=0.629 \mathrm{~mm}, H=7.5 \mathrm{~mm}, Q=4 \mu \mathrm{Lmin}{ }^{-1}$ and $q_{g e n}^{\prime \prime}=$ $1,395 \mathrm{~W} \mathrm{~m}^{-2}$.

transition region, and absorbed film region [25]. The absorbed film region is characterised by long range intermolecular forces. This disjoining pressure result in a flat liquid-vapour interface of a few nanometers thick (10 $20 \mathrm{~nm}$ ) [26] and prevents evaporation occurring in this region [27]. The transition region is defined by growing film thickness which results in a reduction in the long range intermolecular forces. This region experience the highest heat fluxes across the droplet as a result of the low thermal resistance from the small film thickness (1 - $3 \mu \mathrm{m})$ [26]. The total length of the absorbed film and transition region varies from $0.5 \mu \mathrm{m}$ to $10-20 \mu \mathrm{m}$ [26]. As the film thickness increases from the transition region into the intrinsic meniscus and micro-convection regions, so too does the thermal resistance resulting in a drop in the local heat flux. Both the intrinsic meniscus and micro-convection regions are characterised by surface tension and inertial forces [25].

\subsection{Electrospray cooling heat transfer characteristics}

Two distinct electrospray cooling modes were observed during experimentation: evaporative electrospray cooling and pool electrospray cooling. The first corresponds to the case where droplets impinge on the heated substrate, forming multiple individual contact lines, and evaporate [28]. Whereas, pool cooling was denoted by a coalescence of generated droplets on the heated substrate to form a quasi- steady macro-sized liquid film. The first regime was noted for greater separation heights and lower flow rates with the pool mode noted for lower separation heights and larger flow rates.

An example of the evaporative cooling case is shown in Figure 8. Figure $8 \mathrm{a}$ is captured from the optical camera which is focused on the interface between the electrospray plume and the heated substrate. A low power Acculase diode laser fitted with a $9^{\circ}$ line lens is used to illuminate a section of the electrospray plume. The temperature and convective heat flux maps of the foil are shown in Figure 8b with their corresponding radial profiles shown in Figure 8c.

The final plot, Figure 8d, highlights the individual radial energy balance terms of the evaporative electrospray cooling. From this plot it can been seen that peak convective electrospray cooling is located directly below the nozzle, at $S_{x}=0 \mathrm{~mm}$, and corresponds with a value of $6,711 \mathrm{~W} \mathrm{~m}^{-2}$, notably larger than $q_{\text {gen }}^{\prime \prime}$. This convective radial heat flux profile is due to the relatively uniform mass flux $\left(j_{m}\right)$ in the region around $S_{x}=0 \mathrm{~mm}[4,5]$. Both the energy generation term and storage term remain constant at $1,395 \mathrm{~W} \mathrm{~m}^{-2}$ and $24 \mathrm{~W} \mathrm{~m}^{-2}$ respectively as the radial distance from the centre of the source nozzle increases. In the case of $q_{\text {gen }}^{\prime \prime}$ this is due to the uniform heat generation through the foil and paint layers. The low value of $q_{\text {cap }}^{\prime \prime}$ for all values of $S_{x}$ demonstrates the quasi-steady nature of the electrospray cooling process. Examining each 


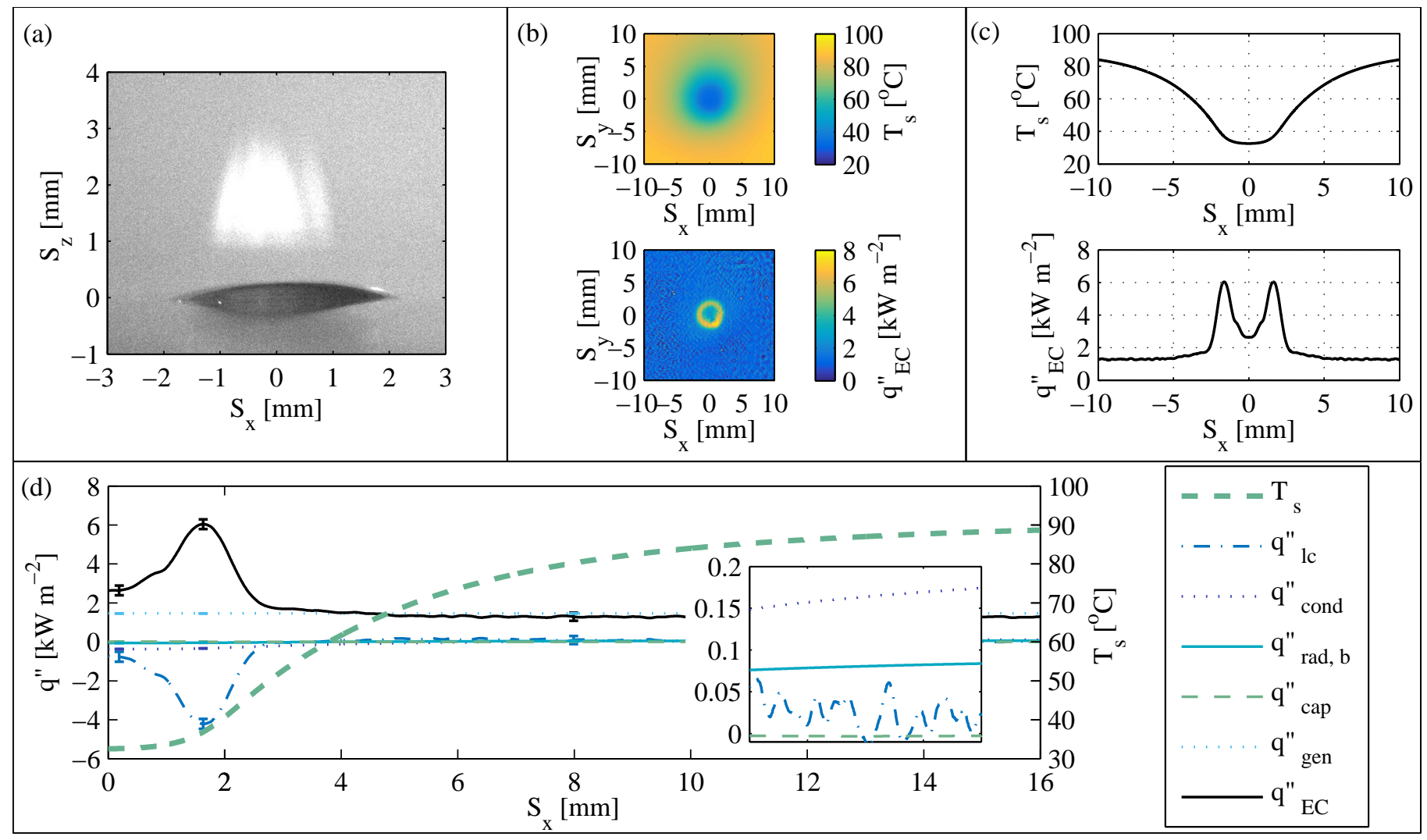

Figure 9: Radial pooling energy balance. $V_{n}=3.2 \mathrm{kV}, D_{i}=0.330 \mathrm{~mm}, D_{o}=0.629 \mathrm{~mm}, H=7.5 \mathrm{~mm}, Q=16 \mu \mathrm{Lmin}{ }^{-1}$ and $q_{g e n}^{\prime \prime}=$ $1,395 \mathrm{~W} \mathrm{~m}^{-2}$.

term moving radially outward from the centre for $S_{x}=0-$ $4 \mathrm{~mm}$, it can be seen that the magnitude of $q_{E C}^{\prime \prime}$ decreases steadily across this region. A peak lateral conduction value $\left(q_{l c}^{\prime \prime}=5,071 \mathrm{~W} \mathrm{~m}^{-2}\right)$ is noted at $S_{x}=0 \mathrm{~mm}$ due to the high thermal gradients in the central region $\left(\partial T / d S_{x}=\right.$ $4.96^{\circ} \mathrm{C} \mathrm{mm}^{-1}$ ) resulting from the high convective heat flux caused by the evaporation of impacting droplets. From $S_{x}=4-16 \mathrm{~mm}$ the convective term $q_{E C}^{\prime \prime}$ remains relatively constant at $\approx 1,120 \mathrm{~W} \mathrm{~m}^{-2}$ and the lateral conduction is low due to the low thermal gradient $\left(\partial T / d S_{x}\right.$ $\left.=1.02^{\circ} \mathrm{C} \mathrm{mm}^{-1}\right)$. The small difference between the $q_{E C}^{\prime \prime}$ and $q_{\text {gen }}^{\prime \prime}\left(\Delta q^{\prime \prime}=275 \mathrm{~W} \mathrm{~m}^{-2}\right)$ is due to the minor yet not negligible $q_{\text {cond }}^{\prime \prime}$ and $q_{\text {rad,b }}^{\prime \prime}$ heat loss terms.

Figure 9 is an example of the pool cooling electrospraying regime. The fixed liquid pool can be clearly seen in Figure 9a. Unlike the previous evaporative case, the convective heat flux distribution (Figure 9b) shows that greatest cooling occurs in the region around triple line region of the quasi-steady film $\left(q_{\text {ec,peak }}^{\prime \prime}=6,043 \mathrm{~W} \mathrm{~m}^{-2}\right.$ and $S_{x, q^{\prime \prime} \text { ec,peak }}$ $=1.64 \mathrm{~mm})$. This profile shape is due to the high evaporation rate at the triple line, and is similar to that observed by Marchuk et al. [24] and Karchevsky et al. [26] in their investigation of the lateral conduction problem for thin foil droplet evaporation. This region experience the highest heat fluxes across the droplet as a result of the low thermal resistance from the small film thickness (1 $3 \mu \mathrm{m})[26]$.
The radial profile of the energy balance (Figure 9d) can be separated into three distinct regions. In the central region, $S_{x}=0-1 \mathrm{~mm}$, it can be seen that the magnitude of $q_{E C}^{\prime \prime} \approx q_{g e n}^{\prime \prime}$. This is due to the low temperature gradient across this region $\left(\partial T / d S_{x}=1.05^{\circ} \mathrm{C} \mathrm{mm}^{-1}\right)$ resulting in low lateral conduction. Similarly, the low temperature value of the foil $\left(\approx 33.12^{\circ} \mathrm{C}\right)$ results in reduced heat losses by conduction and radiation to the IR window from the bottom of the foil. In the second region $\left(S_{x}=1-4 \mathrm{~mm}\right)$, the convective heat flux increases to a peak at the triple contact line, as this is the region where significant evaporation is occurring. Similar to that discussed for the centre region of the evaporative mode, the high convective heat flux causes significant lateral conduction within the foil due to the large induced temperature gradients. In the far-field region, $S_{x}=4-16 \mathrm{~mm}$, the situation is similar to the evaporative regime as there is no longer heat transfer to a liquid phase. For both the evaporative and pool cooling cases, integrating the individual energy balance terms $\left(q_{E C}^{\prime \prime}, q_{l c}^{\prime \prime}, q_{r a d, b}^{\prime \prime}, q_{c o n d}^{\prime \prime}\right.$, and $\left.q_{c a p}^{\prime \prime}\right)$ between $S_{x}$ $=0-16 \mathrm{~mm}$ and dividing by the examined area is found equal to $q_{g e n}^{\prime \prime}$.

\subsection{Cooling regime transition}

The cooling transition point $(C T P)$ between evaporative and pool cooling is dependent on six factors; heated substrate properties, applied generated power, the liquid 

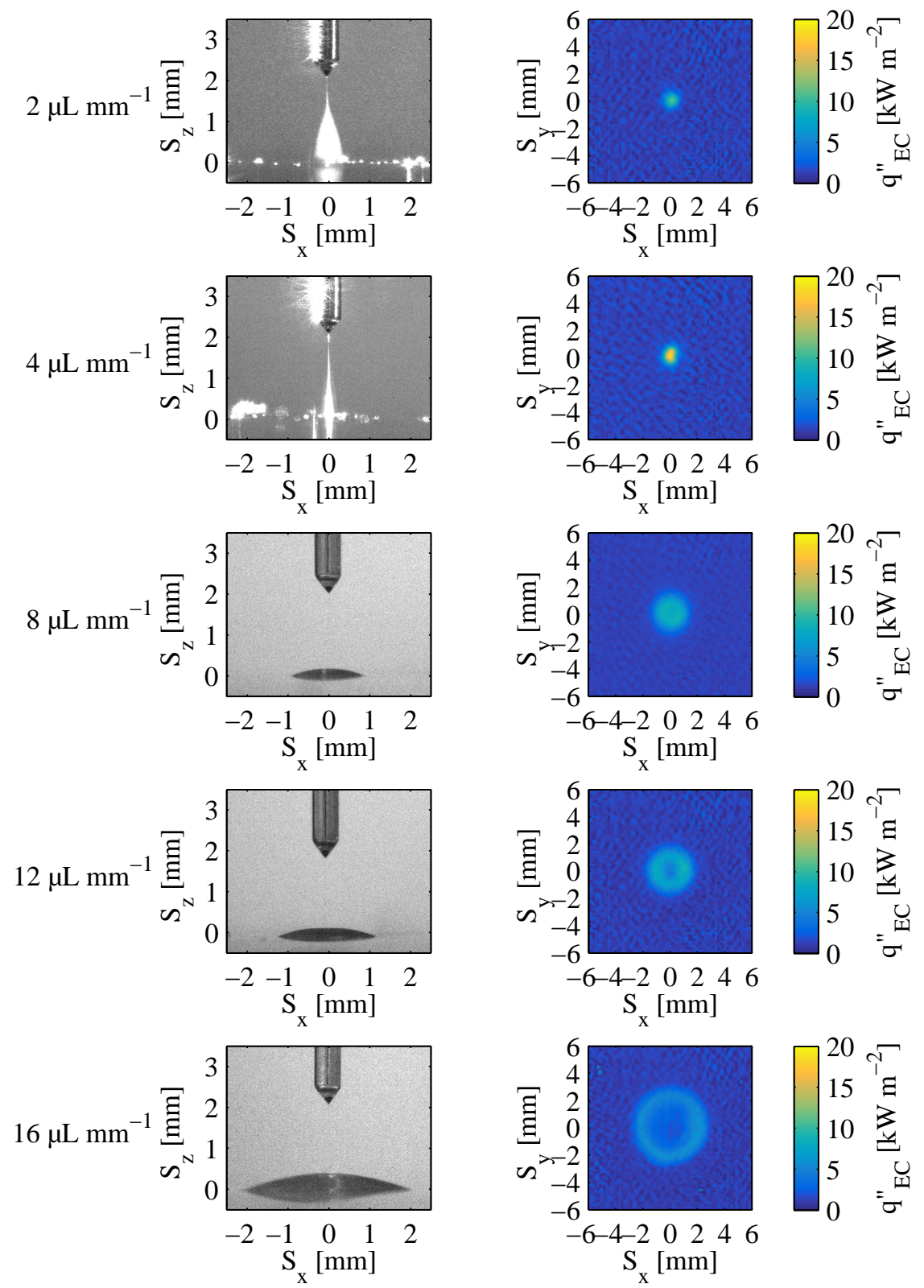
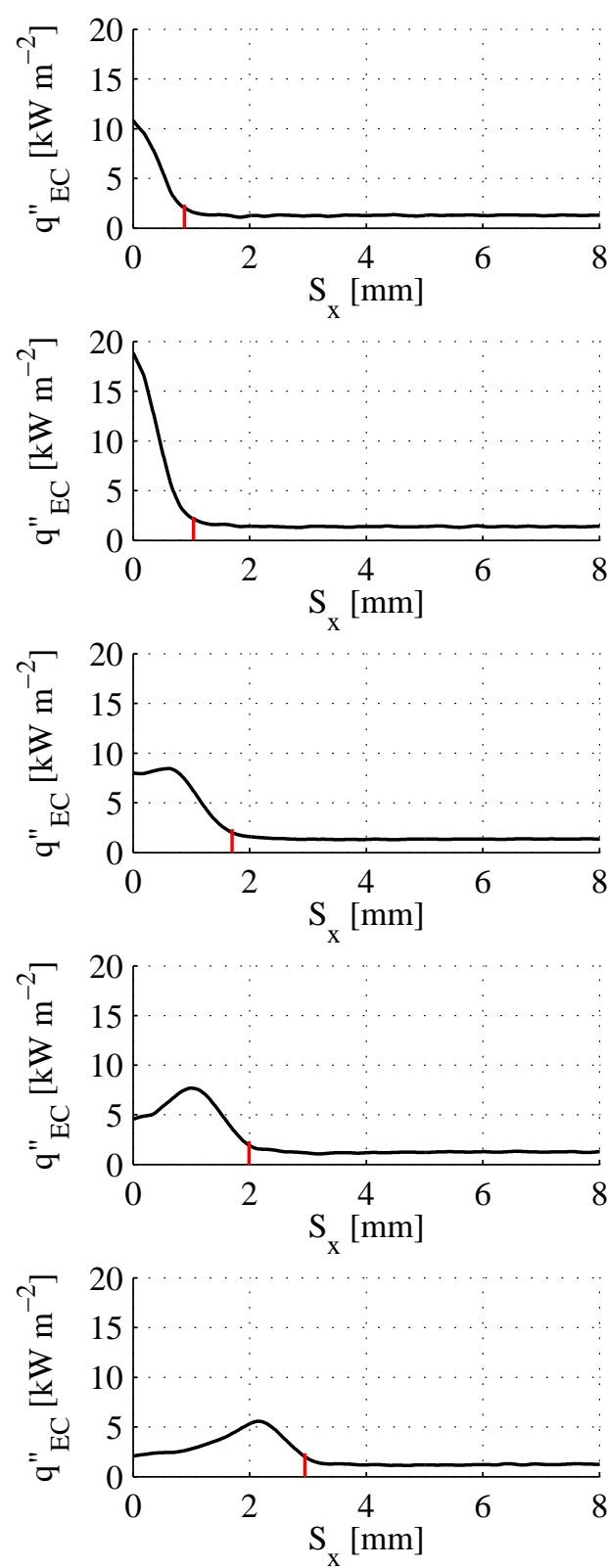

Figure 10: Impact of working fluid flow rate. $V_{n}=1.95-2.15 \mathrm{kV}, Q=2-16 \mu \mathrm{L} \mathrm{min}{ }^{-1}, D_{i}=0.330 \mathrm{~mm}, D_{o}=0.629 \mathrm{~mm}, H=2.5 \mathrm{~mm}$, and $q_{g e n}^{\prime \prime}=1,395 \mathrm{~W} \mathrm{~m}^{-2}$.

mass flux impinging on the surface, the ambient surroundings, and the latent heat of evaporation of the cooling fluid $h_{f g}$, such that:

$$
C T P=f\left(k_{f}, \delta_{f}, q_{g e n}^{\prime \prime}, j_{m}, T_{\infty}, h_{f g}\right)
$$

In the current experimental set-up, the energy available to evaporate an impinging droplet is supplied from that generated, $q_{g e n}^{\prime \prime}$, and that which flows within the foil, $q_{l c}^{\prime \prime}$. Once the mass flux is large enough that the required evaporative heat flux exceeds that which can be supplied by $q_{g e n}^{\prime \prime}$ and $q_{l c}^{\prime \prime}$, pooling of the working fluid on the heated substrate occurs. This is similar to that noted by Horacek et al. [29] and Sodtke and Stephan [30]. They observed a maximum heat flux for the greatest cumulative contact line length density (CLL) ${ }^{1}$. This can be interpreted as the point when numerous droplets, all with their own individual contact lines, are evaporating on the heated substrate. Once the mass flux is increased or, in Horacek et al. [29] and Sodtke and Stephan [30] case, $q_{g e n}^{\prime \prime}$ is decreased, an increased coalescence of impinging droplets is noted resulting in a decrease in CLL and subsequent removed heat flux.

\footnotetext{
${ }^{1} \mathrm{CLL}=$ total contact line length / wetted surface area
} 

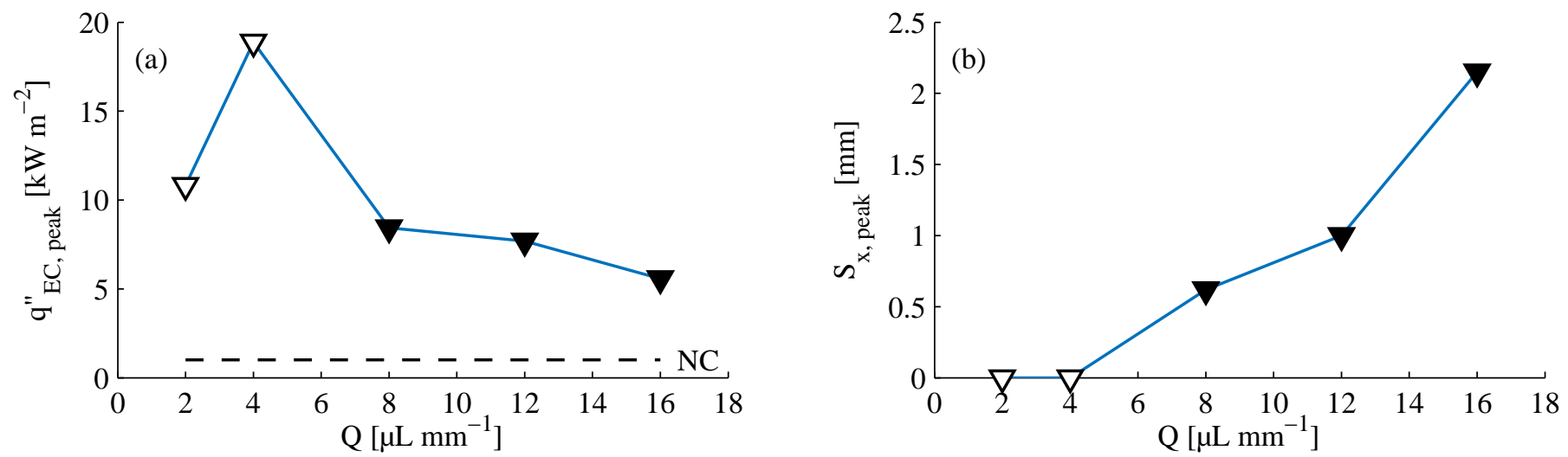

Figure 11: $q_{E C, \text { peak }}^{\prime \prime}$ magnitude and radial location for varying flow rate. $V_{n}=1.95-2.15 \mathrm{kV}, Q=2-16 \mu \mathrm{L} \mathrm{min}{ }^{-1}, D_{i}=0.330 \mathrm{~mm}, D_{o}=$ $0.629 \mathrm{~mm}, H=2.5 \mathrm{~mm}$, and $q_{g e n}^{\prime \prime}=1,395 \mathrm{~W} \mathrm{~m}^{-2}$.

\subsection{Influence of flow rate}

Figure 10 and 11 demonstrates the influence of varying the coolant flow rate on the convective heat transfer. Figure 10 shows the electrospray plume - heated substrate interface (left), the convective heat flux map (middle) and the radial convective profile (right) for $V_{n}=1.95-2.15$ $\mathrm{kV}, Q=2-16 \mu \mathrm{L} \min ^{-1}, D_{i}=0.330 \mathrm{~mm}, D_{o}=0.629$ $\mathrm{mm}, H=2.5 \mathrm{~mm}$, and $q_{g e n}^{\prime \prime}=1,395 \mathrm{~W} \mathrm{~m}^{-2}$. The vertical red lines in the radial convective profile plots of Figure 10 (right) highlight the radial distance from $S_{x}=0 \mathrm{~mm}$ of enhanced cooling by EC $\left(r_{E C}\right)$. This area is defined as the region where the dissipated heat flux is 2 times that of the natural convection case. The empty and filled markers of Figure 11 denote the evaporative and pool electrospray cooling regimes respectively.

As the flow rate is initially increased from $2 \mu \mathrm{L} \mathrm{min}{ }^{-1}$ the peak heat flux, which is initially centrally located, increases (Figures 10 and 11). This is due to increasing droplet mass flux resulting in an increased CLL due to individual impinging droplets. A peak heat flux of $18.87 \mathrm{~kW} \mathrm{~m}^{-2}$ was observed at this point. This corresponded to a 18.71 times enhancement over natural convection. As the flow rate is increased further, cooling transitions from evaporative $\left(2-4 \mu \mathrm{L} \mathrm{min}^{-1}\right)$ to pool electrospray cooling $\left(8-16 \mu \mathrm{L} \min ^{-1}\right)$. As the mass flux is increased from $4-8 \mu \mathrm{L} \mathrm{min}{ }^{-1}$ the required evaporative heat flux exceeds that which can be supplied by the heated substrate, impinging droplet coalesce resulting in pooling of the working fluid on the heated substrate. $q_{\text {EC,peak }}^{\prime \prime}$ decreases due to the reduced CLL and thus increased thermal resistance. The location of this reduced peak heat flux $\left(S_{x, \text { peak }}\right)$ is found in the region around the triple line of the quasi-steady formed liquid droplet. This can be seen from the optical images by the appearance of a visible liquid film on the heated foil surface for the $8 \mu \mathrm{L} \mathrm{min}{ }^{-1}$ case.

After transition to the pool cooling regime, the radial profile shows a decreasing $q_{E C, \text { peak }}^{\prime \prime}$ and increasing $S_{x, \text { peak }}$ with increasing liquid flow rate. This increasing $S_{x, \text { peak }}$ (Figure 11b) is due to the increasing base diameter of the quasi-steady pool from the increasing mass flux. The drop in $q_{E C, \text { peak }}^{\prime \prime}$ can be attributed to the increasing thermal resistance (decreasing CLL) as the pool grows. From Figure 11a one would expect $q_{E C, \text { peak }}^{\prime \prime}$ for this set-up to occur at or just after $4 \mu \mathrm{L} \mathrm{min}{ }^{-1}$. This result demonstrates that increased fluid deposition rate on the surface does not necessarily result in improved local heat transfer, which may be counter intuitive. This is due to the transition to the pool cooling regime, where the electrospray plume becomes more of a fluid delivery system to the fixed pool of liquid on the substrate surface, with heat transfer defined by the singular contact line of the fixed droplet. The higher convective heat fluxes achieved by direct impact of the charged micron sized droplets on the heated substrate are thus diminished in this scenario. For reference, the dashed line in Figure 11a denotes the cooling in the far field of each test corresponding to that of natural convection alone, thus highlighting the notable enhancement that EC has over natural convection.

\subsection{Influence of separation height}

Figure 12 and 13 show the influence of varying the source - target separation height on the electrospray cooling profile, magnitude and position of $q_{E C, \text { peak }}^{\prime \prime}$ for $V_{n}=$ $2.07-4.3 \mathrm{kV}, H=2.5-17.5 \mathrm{~mm}, D_{i}=0.330 \mathrm{~mm}, D_{o}$ $=0.629 \mathrm{~mm}, Q=12 \mu \mathrm{L} \mathrm{min}{ }^{-1}$, and $q_{\text {gen }}^{\prime \prime}=1,395 \mathrm{~W} \mathrm{~m}^{-2}$. The electrospray pool cooling mode is noted at lower separation heights, with transition to the evaporative regime $(H=10-12.5 \mathrm{~mm})$ as $H$ is increased. This is due to decreasing local droplet mass flux as $H$ increases, as a result of greater plume dispersion. As $H$ increases the distance over which the droplets have to spread increases. As the separation height is increased initially $(H=2.5-5 \mathrm{~mm}) \mathrm{a}$ drop in $S_{x, \text { peak }}$ is noted with a modest increase in $q_{E C, p e a k}^{\prime \prime}$ (Figure 13a and b). This is due to the coincidental droplet triple line and primary droplet spray core resulting in a lower thermal resistance in this region. For $H=5-10$ $\mathrm{mm}$ an increase in $S_{x, \text { peak }}$ is coupled with a monotonic

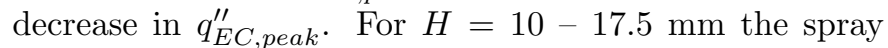
transitions to the evaporative mode, such that $S_{x, \text { peak }}=$ $0 \mathrm{~mm}$ and $q_{E C, \text { peak }}^{\prime \prime}$ continues to decrease as $H$ increases 


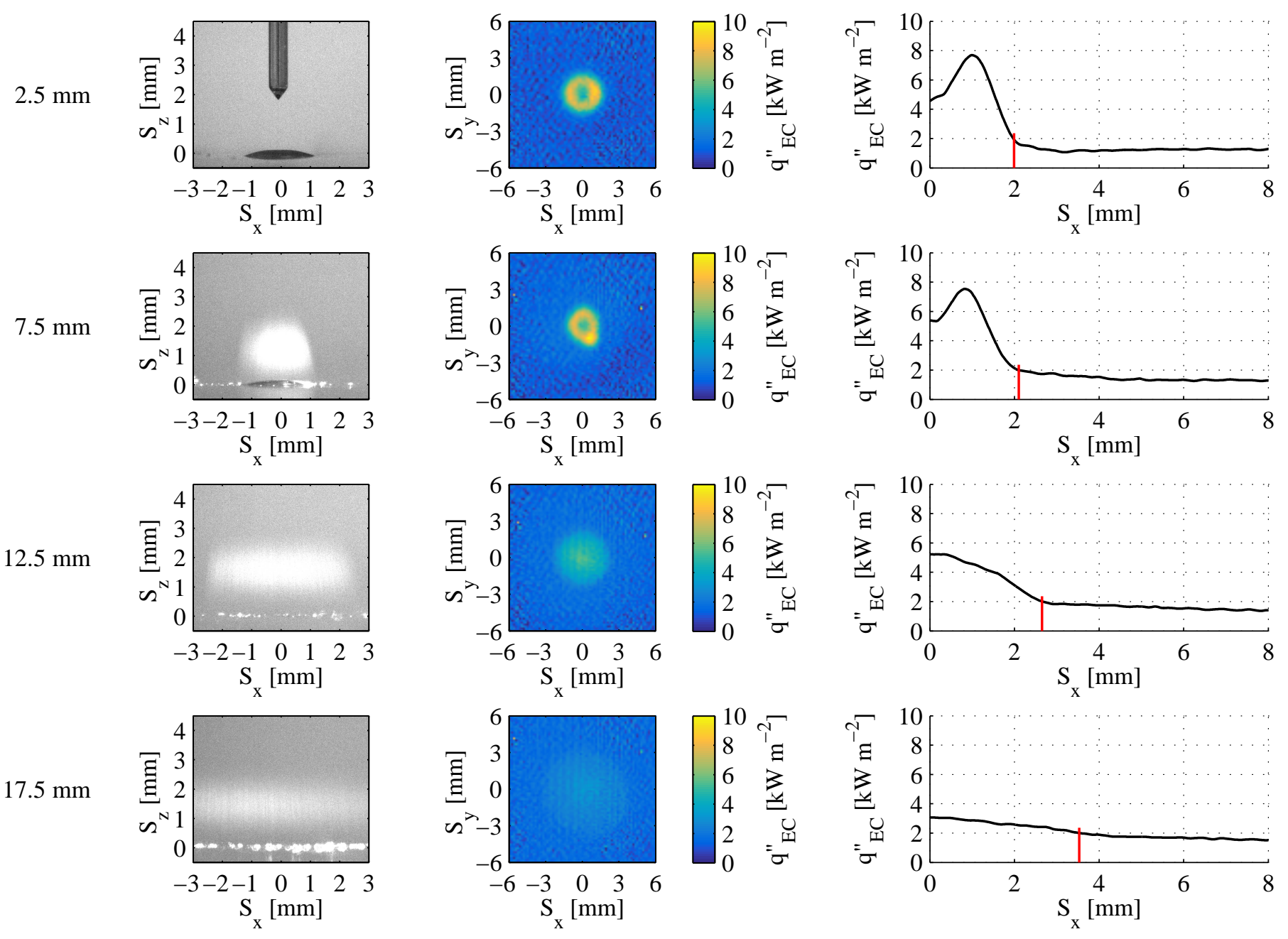

Figure 12: Impact of varied separation height. $V_{n}=2.07-4.3 \mathrm{kV}, H=2.5-17.5 \mathrm{~mm}, D_{i}=0.330 \mathrm{~mm}, D_{o}=0.629 \mathrm{~mm}, Q=12 \mu \mathrm{L} \mathrm{min}-1$, and $q_{g e n}^{\prime \prime}=1,395 \mathrm{~W} \mathrm{~m}^{-2}$.
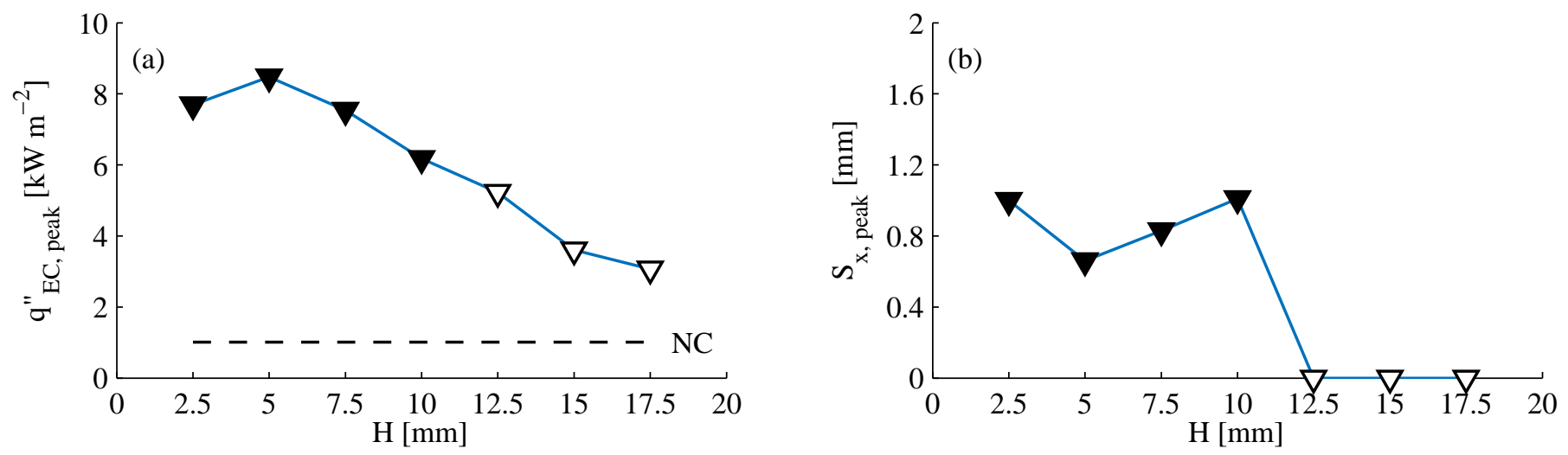

Figure 13: $q_{E C, \text { peak }}^{\prime \prime}$ magnitude and radial location for varying separation height. $V_{n}=2.07-4.3 \mathrm{kV}, H=2.5-17.5 \mathrm{~mm}, D_{i}=0.330 \mathrm{~mm}$, $D_{o}=0.629 \mathrm{~mm}, Q=12 \mu \mathrm{Lmin}^{-1}$, and $q_{g e n}^{\prime \prime}=1,395 \mathrm{~W} \mathrm{~m}^{-2}$.

due to the reduced mass flux of the droplets striking the surface due to the greater plume dispersion. This is confirmed by the radial plots of Figure 12 for the $H=12.5-$ $17.5 \mathrm{~mm}$ cases, where it can be seen that as the separation height is increased a greater area of the substrate is cooled due to droplet dispersion, albeit at a lower $q_{E C}^{\prime \prime}$ magnitude due to the lower local mass flux. 

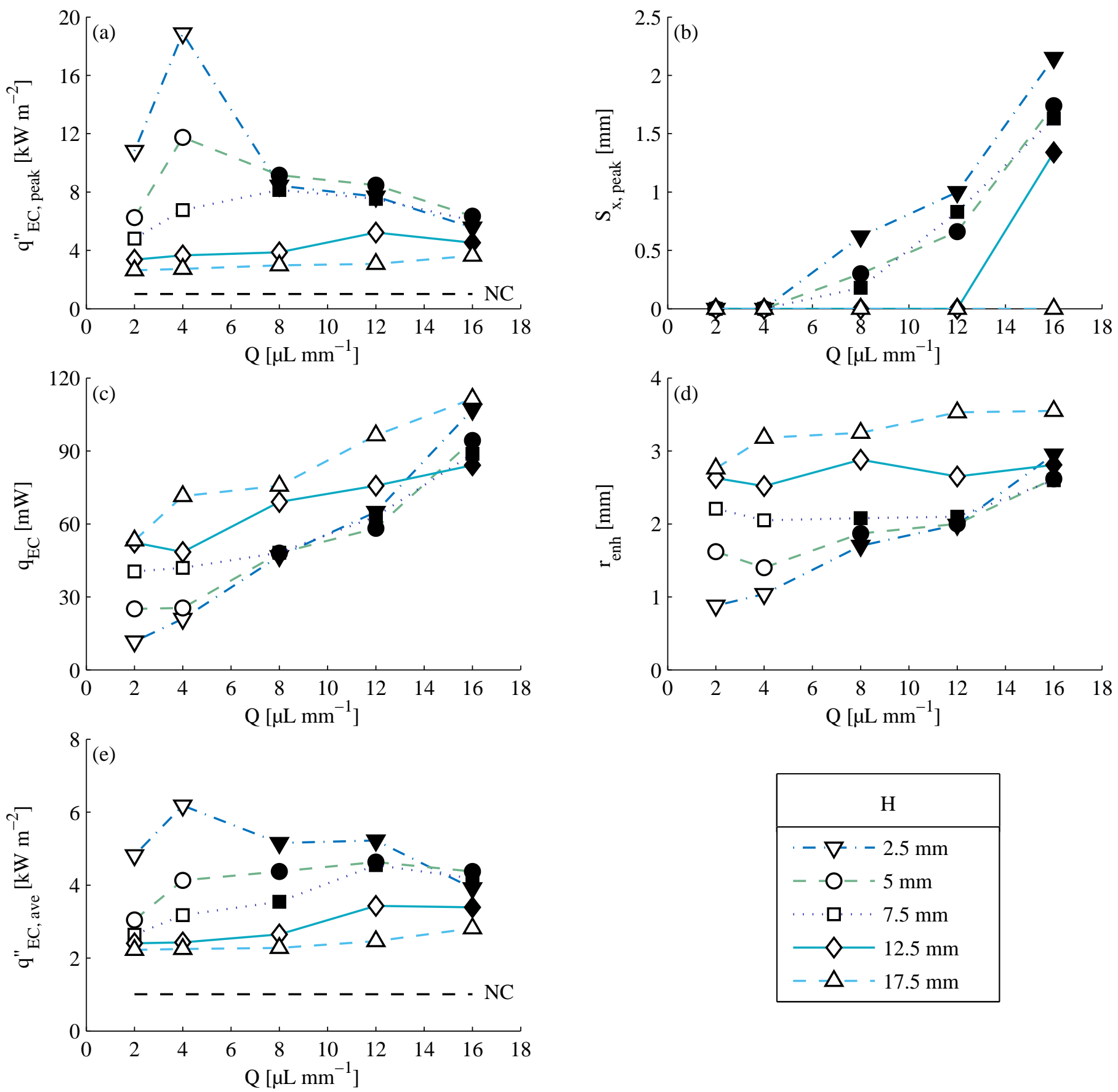

Figure 14: Electrospray cooling performance for varying flow rate and separation height. (a) peak heat flux, (b) peak heat flux location, (c) thermal power, (d) radial heat transfer enhancement, and (e) average heat flux over the area of heat transfer enhancement. $V_{n}=1.95-4.67$ $\mathrm{kV}, Q=2-16 \mu \mathrm{Lmin}{ }^{-1}, H=2.5-17.5 \mathrm{~mm}, D_{i}=0.330 \mathrm{~mm}, D_{o}=0.629 \mathrm{~mm}$, and $q_{g e n}^{\prime \prime}=1,395 \mathrm{~W} \mathrm{~m}^{-2}$

\subsection{Parametric study}

Figures 14 and 15 are an attempt to synthesise the trends related to the working fluid flow rate, separation height, and nozzle size, with empty and filled markers denoting the evaporative and pool electrospray cooling regimes respectively. Figure 14 demonstrates the influence of separation height and flow rate on $q_{E C, p e a k}^{\prime \prime}, S_{x, p e a k}$, $q_{E C}, r_{E C}$, and $q_{E C, \text { ave }}^{\prime \prime}$. Where $q_{E C}$ and $q_{E C, \text { ave }}^{\prime \prime}$ are the thermal power and average heat flux to EC over the region of enhanced cooling $\left(S_{x}=0-r_{E C} \mathrm{~mm}\right) . V_{n}=1.95-4.67$ $\mathrm{kV}, Q=2-16 \mu \mathrm{L} \min ^{-1}, H=2.5-17.5 \mathrm{~mm}, D_{i}=0.330$ $\mathrm{mm}, D_{o}=0.629 \mathrm{~mm}$, and $q_{\text {gen }}^{\prime \prime}=1,395 \mathrm{~W} \mathrm{~m}^{-2}$.

For a fixed $H, q_{E C, \text { peak }}^{\prime \prime}$ increases with increasing $Q$ in the evaporative regime due to the associated increase in droplet mass flux and subsequent CLL on the heated substrate. However, transition to pool cooling occurs when the combination of the internal heat generation and lateral conduction is insufficient to supply the energy required 
to evaporate the impinging droplets. The highest values of $q_{E C, \text { peak }}^{\prime \prime}$ for a given separation height are observed close to the transition from evaporative to pool cooling (CTP), with higher values of $q_{E C, p e a k}^{\prime \prime}$ occurring for smaller separation heights and lower flow rates. This can be attributed to a thinner liquid films due to smaller produced droplet from lower liquid flow rates. The relationships between $H$ and $Q$ with CTP are shown in Figure 14a, transition from evaporative to pool cooling occurs at lower flow rates for reduced separation heights. Plume dispersion increases as $H$ increases, resulting in a drop in the liquid mass flux for a fixed flow rate. Thus, an increased $Q$ is required to induce regime transition for increasing $H$. For evaporative cooling the magnitude of $q_{E C \text {,peak }}^{\prime \prime}$ decreases as $H$ increases. This is due to the reduced spreading of the electrospray plume at lower separation heights and the radial nature of the system. As $H$ is increased the area over which the plume is acting increases parabolically, which decreases the mass
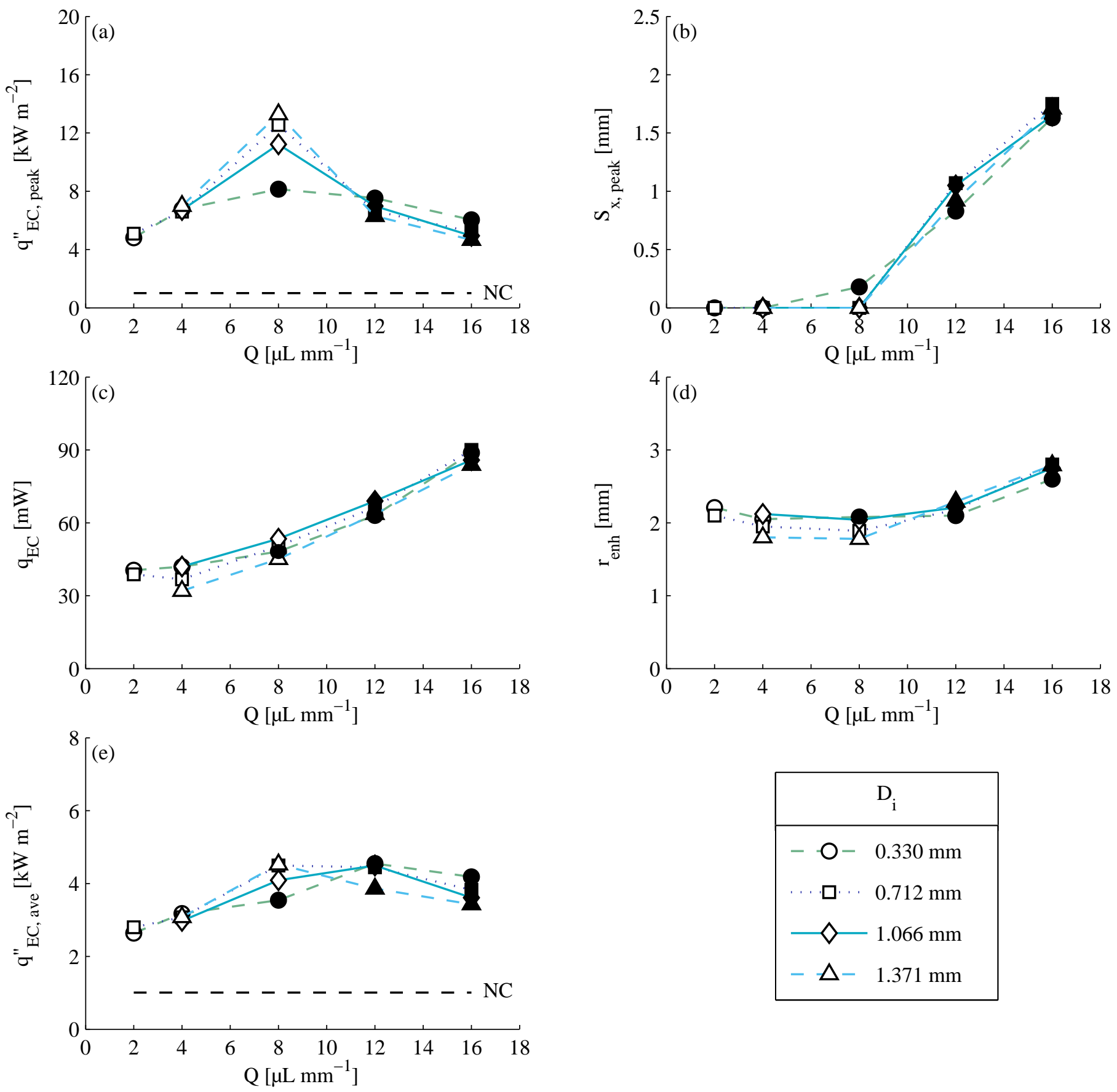

Figure 15: Electrospray cooling performance for varying flow rate and nozzle size. (a) peak heat flux, (b) peak heat flux location, (c) thermal power, (d) radial heat transfer enhancement, and (e) average heat flux over the area of heat transfer enhancement. $V_{n}=2.95-4.08 \mathrm{kV}, Q$ $=2-16 \mu \mathrm{L} \mathrm{min}^{-1}, D_{i}=0.330-1.371 \mathrm{~mm}, D_{o}=0.629-1.844 \mathrm{~mm}, H=7.5 \mathrm{~mm}$ and $q_{\text {gen }}^{\prime \prime}=1,395 \mathrm{~W} \mathrm{~m}^{-2}$. 
flux dramatically for modest increase in $H$.

Once transition to pool cooling occurs, $q_{E C, \text { peak }}^{\prime \prime}$ is largely insensitive to $H$ as cooling is governed by triple line evaporation. For a fixed $Q$ in the pool regime, $S_{x, p e a k}$ decreases as $H$ increases. This can be attributed to increased droplet evaporation due to increasing transit times and decreasing $j_{m}$ as $H$ increases. In the pool regime for a fixed $H$, as $Q$ increases $q_{E C \text {,peak }}^{\prime \prime}$ decreases and $S_{x, \text { peak }}$ increases. This is due to the increasing mass flux causing an increased droplet thickness and spreading, resulting in lower CLL.

Figure $14 \mathrm{c}$ and d demonstrate the relationship between $q_{E C}$ and $r_{E C}$ for varied flow rate and separation height. In general, $q_{E C}$ increases with increasing flow rate independent of cooling regime for all separation heights. Greater values of $q_{E C}$ are noted for increasing values of $H$ in the evaporative regime. This is due to increased plume dispersion with increasing $H$, resulting in increased CLL due to reduced droplet coalescence on the heated substrate during cooling. In the pool regime, $q_{E C}$ is dominated by the contact line length of the quasi-steady macro-sized droplet on the heated substrate. This results in similar values of $q_{E C}$ despite the varied separation height, as the electrospray is acting as a fluid delivery method to a fixed macro-sized droplet. $r_{E C}$ increases with increasing values of $H$ in the evaporative regime (Figure 14d). This is as a result of the increased plume dispersion as $H$ increases. $r_{E C}$ is observed to be largely independent of $Q$ for a fixed $H$ in the evaporative regime. In contrast, $r_{E C}$ increases as $Q$ increases in the pool cooling mode. This is due to the growing macro-sized quasi-steady droplet as $Q$ increases.

Figure 14e plots the average heat flux dissipated by the impinging electrospray plume over the region of enhanced cooling (Figure 14d). The trends in $q_{E C, a v e}^{\prime \prime}$ for varied $H$ and $Q$ are largely similar as $q_{E C, p e a k}^{\prime \prime}$ observed in Figure 14a. A peak average enhancement of 6.1 times over natural convection is noted for $Q=4 \mu \mathrm{L} \mathrm{min}{ }^{-1}$ and $H=$ $2.5 \mathrm{~mm}$. This enhanced cooling was over a circular area of $r_{E C}=1.04 \mathrm{~mm}$. Comparing Figure 14c, d and e, the greatest thermal dissipation and area of enhanced cooling were achieved for the greatest separation height and flow rate $\left(Q=16 \mu \mathrm{L} \mathrm{min}{ }^{-1}\right.$ and $\left.H=17.5 \mathrm{~mm}\right)$. Whereas, the largest average heat flux is noted at the lowest separation height and second smallest flow rate $\left(Q=4 \mu \mathrm{L} \mathrm{min}{ }^{-1}\right.$ and $H=2.5 \mathrm{~mm}$ ) for the second smallest enhanced cooling area. Thus, if the objective is to remove the largest thermal energy the greatest flow rate and separation height are favourable in the evaporative regime prior to CTP. Alternatively, if the goal to to remove the maximum heat flux the lowest separation height and maximum flow rate in the evaporative regime prior to CTP is desired.

Figure 15 shows the influence of varied nozzle size on EC for $V_{n}=2.95-4.08 \mathrm{kV}, Q=2-16 \mu \mathrm{Lmin}^{-1}, D_{i}$ $=0.330-1.371 \mathrm{~mm}, D_{o}=0.629-1.844 \mathrm{~mm}, H=7.5$ $\mathrm{mm}$ and $q_{\text {gen }}^{\prime \prime}=1,395 \mathrm{~W} \mathrm{~m}^{-2}$. Figure $15 \mathrm{a}$ - e demonstrate similar trends in cooling parameters for varied $Q$ as that observed in Figure 14. Electrospray cooling is observed to be largely insensitive to varied nozzle diameter over all examined parameters (Figure 15a - e). If the base of the liquid cone is greater than the acceleration zone base then the jet break up is similar regardless of nozzle size [2].

For $Q=8 \mu \mathrm{L} \mathrm{min}^{-1}$ and $D_{i}=0.330 \mathrm{~mm}$ (Figure 15a), a drop in $q_{E C, \text { peak }}^{\prime \prime}$ is observed due to its early transition to pool cooling in comparison with the other nozzle sizes examined. This early transition can be accounted for as CTP occurs near this point. Eyring et al [31] derived a formula for the electric field between a hyperboloid and plate. Applying this formula, the applied average electric field for the smallest nozzle $\left(D_{i}=0.330 \mathrm{~mm}\right.$ and $D_{o}=$ $0.629 \mathrm{~mm}$ ) is shown to be 1.26 times greater than the next smallest nozzle of $D_{o}=1.095 \mathrm{~mm}$. Yang et al. [32] showed that an increasing applied average electric field results in a reduction of the radial spread of the the primary droplet core resulting in an increase in the mass flux around $S_{x, p e a k}$ $=0 \mathrm{~mm}$. These factors combine to account for the early onset of pool cooling for the smallest nozzle size.

\section{Conclusion}

A parametric study of a single source electrospray was carried out using thin foil thermography to investigate, for the first time, the local convective heat transfer to a single source electrospray. Two distinct cooling regimes were observed; evaporative and pool electrospray cooling. The evaporative regime was shown to exist at greater separation heights and lower flow rates, with the converse true for pool cooling. Neither were shown to have a significant dependence on nozzle size.

In the evaporative regime an increase in working fluid flow rate caused an increase in the peak and average convective heat flux and thermal power dissipated with only marginal change noted in the area of enhanced cooling. In the pool cooling regime an increase in working fluid flow rate was shown to decrease the peak and average convective heat flux while increasing the thermal power, radial location of this peak heat flux and the area of enhanced cooling. In the evaporative regime an increase in the separation height caused a decrease in the average and peak convective heat flux, while an increase in the thermal power dissipated and area of enhanced electrospray cooling was observed. For the pooling case, an increase in the separation height resulted in an decrease in $q_{E C \text {,ave }}^{\prime \prime}$ and $S_{x, \text { peak }}$ with no great dependency noted for other parameters. This is attributed to the spread of the primary droplet spray core being greater than the base diameter of the quasi-steady macro-sized droplet for larger separation heights. For nozzle size, only a small dependency was observed in the evaporative regime for low flow rates and the smallest nozzle size. Nozzle size was shown to be largely independent for both cooling regimes otherwise.

The largest values of $q_{E C, \text { peak }}^{\prime \prime}$ and $q_{E C, \text { ave }}^{\prime \prime}$ were noted for the evaporative regime prior to CTP at the smallest separation heights. These result are similar to that observed by Horacek et al. [29] and Sodtke and Stephan [30]. Both authors noted that the peak heat flux corresponds to 
the point where the fluid deposited on the heated substrate achieve the greatest CLL (evaporative cooling, impact and subsequent spreading of individual droplets on the surface results in formation of multiple contact lines) and that the heat flux decreased with increased wetted area (pool cooling). A peak heat flux of $18.87 \mathrm{~kW} \mathrm{~m}^{-2}$ was observed in the evaporative regime at $H=2.5 \mathrm{~mm}, Q=4 \mu \mathrm{L} \mathrm{min}^{-1}$, $D_{i}=0.330 \mathrm{~mm}, D_{o}=0.629 \mathrm{~mm}$, and $V_{n}=2.03 \mathrm{kV}$. This corresponded to a heat transfer enhancement of 18.71 times over natural convection.

The results of this work highlight the importance of the local droplet mass flux on the convective heat flux as well as heat transfer regime. In general, any parameter change that tends to increase the droplet mass flux also increases the convective heat flux in the evaporative cooling regime. However, due to the limited thermal energy that can be supplied due to the internal generation and lateral conduction, transition to pool cooling occurs when insufficient energy can be supplied to accommodate full evaporation of the impinging droplets. Both regimes are observed to be dependent on triple line heat transfer; evaporative due to the multiple contact lines induced by impacting and spreading of droplets, while pool cooling is governed by the much larger singular contact line established by the quasi-steady macro-sized droplet formed on the heated substrate. Further investigation into the fundamentals of triple line evaporation are required to fully understand the heat and mass transfer from the heated substrate by spray cooling.

\section{Nomenclature}

$C_{p} \quad$ Specific heat capacity $\left[\mathrm{J} \mathrm{kg}^{-1} \mathrm{~K}^{-1}\right]$

$D_{d} \quad$ Primary droplet diameter $[\mu \mathrm{m}]$

$D_{i} \quad$ Source nozzle inner diameter $[\mathrm{mm}]$

$D_{j} \quad$ Jet diameter $[\mu \mathrm{m}]$

$D_{o} \quad$ Source nozzle outer diameter [mm]

$E \quad$ Energy [J]

$H$ Source - target separation height [mm]

I Current $[\mathrm{A}]$

$j_{m} \quad$ Mass flux $\left[\mathrm{kg} \mathrm{m}^{-2} \mathrm{~s}^{-1}\right]$

$k$ Thermal conductivity $\left[\mathrm{W} \mathrm{m}^{-1} \mathrm{~K}^{-1}\right]$

$L$ length [mm]

$Q \quad$ Working fluid flow rate $\left[\mu \mathrm{L} \mathrm{min}^{-1}\right]$

$q \quad$ Heat transfer rate $[\mathrm{W}]$

$q^{\prime \prime} \quad$ Heat flux $\left[\mathrm{W} \mathrm{m}^{-2}\right]$

$r$ Radial distance from nozzle centre [mm]

$S$ Coordinate [mm]

$T$ Temperature $[\mathrm{K}]$

$V \quad$ Voltage [V]

Dimensionless Numbers

$\mathrm{Bi} \quad$ Biot number, $\mathrm{Bi}=h L / k[-]$

Oh Ohnesorge number, $\mathrm{Oh}=\mu /\left(\rho \gamma \mathrm{D}_{d}\right)^{1 / 2}[-]$

We Weber number, We $=\rho \mathrm{U}^{2} \mathrm{~d}_{d} / \gamma[-]$ $\delta \quad$ Thickness $[\mu \mathrm{m}]$

$\gamma$ Surface tension $\left[\mathrm{N} \mathrm{m}^{-1}\right]$

$\rho$ Density $\left[\mathrm{kg} \mathrm{m}^{-3}\right]$

$\sigma \quad$ Stefan-Boltzmann constant $\left[\mathrm{W} \mathrm{m}^{-2} \mathrm{~K}^{-4}\right]$

$\varepsilon \quad$ Emissivity [-]

Subscripts

$\infty \quad$ Bulk or infinity

ag Air gap

cap Capacitive or storage

cond Conduction

d Droplet

enh Heat transfer enhancement

$f \quad$ Foil

gen Generated

lc Lateral conduction

$n \quad$ Source nozzle

$p \quad$ Paint

rad Radiation

$s \quad$ Heated substrate

$w f \quad$ Working fluid

$x, y, z \quad$ Coordinate direction

Acronyms

CLL Contact line length density

DC Direct current

EC Electrospray cooling

EU Expanded uncertainty

IR Infrared

NC Natural convection

NI National instrument

PU Percentage uncertainty

PEEK Polyether ether ketone

\section{Acknowledgements}

The authors would like to acknowledge the financial support of the Irish Research Council under Grant No. $\mathrm{RS} / 2012 / 86$.

\section{References}

[1] M. Cloupeau, B. Prunet-Foch, Electrostatic spraying of liquids in cone-jet mode, Journal of Electrostatics 22 (2) (1989) 135159.

[2] M. Cloupeau, B. Prunet-Foch, Electrostatic spraying of liquids: main functioning modes, Journal of Electrostatics 25 (2) (1990) 165-184.

[3] W. Deng, A. Gomez, Electrospray cooling for microelectronics, International Journal of Heat and Mass Transfer 54 (11) (2011) $2270-2275$.

[4] K. Tang, A. Gomez, On the structure of an electrostatic spray of monodisperse droplets, Physics of Fluids 6 (7) (1994) 23172332 .

[5] O. Wilhelm, L. Madler, S. E. Pratsinis, Electrospray evaporation and deposition, Journal of Aerosol Science 34 (7) (2003) $815-836$.

Greek symbols 
[6] J. Fernández De La Mora, J. Navascues, F. Fernandez, J. RosellLlompart, Generation of submicron monodisperse aerosols in electrosprays, Journal of Aerosol Science 21 (1990) 673-676.

[7] D. R. Chen, D. Y. H. Pui, S. L. Kaufman, Electrospraying of conducting liquids for monodisperse aerosol generation in the 4 $\mathrm{nm}$ to $1.8 \mu \mathrm{m}$ diameter range, Journal of Aerosol Science 26 (6) (1995) 963-977.

[8] W. Deng, A. Gomez, The role of electric charge in microdroplets impacting on conducting surfaces, Physics of Fluids 22 (5) (2010) 051703.

[9] X. Feng, J. E. Bryan, Application of electrohydrodynamic atomization to two-phase impingement heat transfer, Journal of Heat Transfer 130 (7) (2008) 072202.

[10] H. C. Wang, A. V. Mamishev, Optimal heat transfer performance of the microfluidic electrospray cooling devices, in: 27th Annual Semiconductor Thermal Measurement and Management Symposium, IEEE, 2011, pp. 35-42.

[11] H. C. Wang, A. V. Mamishev, Heat transfer correlation models for electrospray evaporative cooling chambers of different geometry types, Applied Thermal Engineering 40 (2012) 91-101.

[12] D. B. Donoghue, A. Albadawi, Y. M. C. Delaure, A. J. Robinson, D. B. Murray, Bubble impingement and the mechanisms of heat transfer, International Journal of Heat and Mass Transfer 71 (2014) 439-450.

[13] O. Raghu, J. Philip, Thermal properties of paint coatings on different backings using a scanning photo acoustic technique, Measurement Science and Technology 17 (11) (2006) 2945.

[14] T. L. Bergman, F. P. Incropera, A. S. Lavine, Fundamentals of heat and mass transfer, Wiley, 2011.

[15] L. Kirkup, R. B. Frenkel, An Introduction to Uncertainty in Measurement: Using the GUM (Guide to the Expression of Uncertainty in Measurement), Cambridge University Press, 2006.

16] R. Hartman, D. Brunner, D. Camelot, J. Marijnissen, B. Scarlett, Electrohydrodynamic atomization in the cone-jet mode physical modeling of the liquid cone and jet, Journal of Aerosol science 30 (7) (1999) 823-849.

[17] M. Cloupeau, B. Prunet-Foch, Electrohydrodynamic spraying functioning modes: a critical review, Journal of Aerosol Science 25 (6) (1994) 1021-1036.

[18] K. Tang, A. Gomez, Generation by electrospray of monodisperse water droplets for targeted drug delivery by inhalation, Journal of Aerosol Science 25 (6) (1994) 1237-1249.

[19] O. V. Salata, Tools of nanotechnology: Electrospray, Current Nanoscience 1 (1) (2005) 25-33.

[20] A. J. Mestel, The electrohydrodynamic cone-jet at high reynolds number, Journal of Aerosol Science 25 (6) (1994) 1037-1047.

[21] A. Gomez, K. Tang, Charge and fission of droplets in electrostatic sprays, Physics of Fluids 6 (1) (1994) 404-414.

[22] W. Deng, A. Gomez, Influence of space charge on the scale-up of multiplexed electrosprays, Journal of Aerosol Science 38 (10) (2007) 1062-1078.

[23] A. M. Ganan-Calvo, J. C. Lasheras, J. Dávila, A. Barrero, The electrostatic spray emitted from an electrified conical meniscus, Journal of Aerosol Science 25 (6) (1994) 1121-1142.

[24] I. Marchuk, A. Karchevsky, A. Surtaev, O. Kabov, Heat flux at the surface of metal foil heater under evaporating sessile droplets, International Journal of Aerospace Engineering 2015.

[25] P. A. Raghupathi, S. G. Kandlikar, Contact line region heat transfer mechanisms for an evaporating interface, International Journal of Heat and Mass Transfer 95 (2016) 296-306.

[26] A. L. Karchevsky, I. V. Marchuk, O. A. Kabov, Calculation of the heat flux near the liquid-gas-solid contact line, Applied Mathematical Modelling 40 (2) (2016) 1029-1037.

[27] J. N. Israelachvili, Intermolecular and surface forces, Academic press, 1992.

[28] V. S. Ajaev, O. A. Kabov, Heat and mass transfer near contact lines on heated surfaces, International Journal of Heat and Mass Transfer 108 (2017) 918-932.

[29] B. Horacek, K. Kiger, J. Kim, Single nozzle spray cooling heat transfer mechanisms, International Journal of Heat and Mass Transfer 48 (8) (2005) 1425-1438.
[30] C. Sodtke, P. Stephan, Spray cooling on micro structured surfaces, International Journal of Heat and Mass Transfer 50 (19) (2007) 4089-4097.

[31] C. F. Eyring, S. S. Mackeown, R. A. Millikan, Fields currents from points, Physical Review 31 (5) (1928) 900.

[32] W. Yang, B. Lojewski, Y. Wei, W. Deng, Interactions and deposition patterns of multiplexed electrosprays, Journal of Aerosol Science 46 (2012) 20-33. 